\title{
Source apportionment of ambient particle number concentrations in central Los Angeles using positive matrix factorization (PMF)
}

\author{
Mohammad Hossein Sowlat, Sina Hasheminassab, and Constantinos Sioutas \\ University of Southern California, Department of Civil and Environmental Engineering, Los Angeles, CA, USA \\ Correspondence to: Constantinos Sioutas (sioutas@usc.edu)
}

Received: 25 November 2015 - Published in Atmos. Chem. Phys. Discuss.: 3 February 2016

Revised: 31 March 2016 - Accepted: 1 April 2016 - Published: 20 April 2016

\begin{abstract}
In this study, the positive matrix factorization (PMF) receptor model (version 5.0) was used to identify and quantify major sources contributing to particulate matter (PM) number concentrations, using PM number size distributions in the range of $13 \mathrm{~nm}$ to $10 \mu \mathrm{m}$ combined with several auxiliary variables, including black carbon (BC), elemental and organic carbon (EC/OC), PM mass concentrations, gaseous pollutants, meteorological, and traffic counts data, collected for about 9 months between August 2014 and 2015 in central Los Angeles, CA. Several parameters, including particle number and volume size distribution profiles, profiles of auxiliary variables, contributions of different factors in different seasons to the total number concentrations, diurnal variations of each of the resolved factors in the cold and warm phases, weekday/weekend analysis for each of the resolved factors, and correlation between auxiliary variables and the relative contribution of each of the resolved factors, were used to identify PM sources. A six-factor solution was identified as the optimum for the aforementioned input data. The resolved factors comprised nucleation, traffic 1, traffic 2 (with a larger mode diameter than traffic 1 factor), urban background aerosol, secondary aerosol, and soil/road dust. Traffic sources (1 and 2) were the major contributor to PM number concentrations, collectively making up to above $60 \%(60.8-68.4 \%)$ of the total number concentrations during the study period. Their contribution was also significantly higher in the cold phase compared to the warm phase. Nucleation was another major factor significantly contributing to the total number concentrations (an overall contribution of $17 \%$, ranging from 11.7 to $24 \%$ ), with a larger contribution during the warm phase than in the cold phase. The other identified factors were urban background aerosol, secondary aerosol, and soil/road dust, with relative contributions of ap-
\end{abstract}

proximately $12 \%(7.4-17.1), 2.1 \%(1.5-2.5 \%)$, and $1.1 \%$ $(0.2-6.3 \%)$, respectively, overall accounting for about $15 \%$ (15.2-19.8\%) of PM number concentrations. As expected, PM number concentrations were dominated by factors with smaller mode diameters, such as traffic and nucleation. On the other hand, PM volume and mass concentrations in the study area were mostly affected by sources with larger mode diameters, including secondary aerosols and soil/road dust. Results from the present study can be used as input parameters in future epidemiological studies to link PM sources to adverse health effects as well as by policymakers to set targeted and more protective emission standards for PM.

\section{Introduction}

Numerous epidemiological studies have provided compelling evidence linking exposure to ambient particulate matter (PM) with increased risk of respiratory and cardiovascular diseases, hospitalization, and premature mortality (Brunekreef and Forsberg, 2005; Dockery and Stone, 2007; Miller et al., 2007; Pope et al., 2004, 2002; Gauderman et al., 2015). According to the most recent global burden of disease study, over 3 million premature deaths occur annually all around the globe due to exposure to ambient PM (Lim et al., 2013). It should, however, be noted that most of these epidemiological studies have related the aforementioned health outcomes with solely the mass concentrations of PM and, therefore, do not adequately represent submicron particles (Ogulei et al., 2007), mainly because this PM fraction contributes negligibly to total ambient PM mass (Delfino et al., 2005; Vu et al., 2015). More recently, studies have associated human health effects with particles characteristics other 
than mass concentration, including size, number concentration, chemical composition, and even surface area (Brook et al., 2010; Kasumba et al., 2009; Lighty et al., 2000; Chen et al., 1991; Dreher et al., 1997; Oberdörster et al., 1994; Peters et al., 1997; Delfino et al., 2010; Davis et al., 2013). Even though our knowledge of which particle characteristic (mass, size, surface area, etc.) can be considered as the best predictor for human health outcomes is limited, there is growing evidence highlighting the critical role of particle size and number concentrations from a human health effect perspective (Vu et al., 2015). For example, studies have indicated that ultrafine particles (UFPs, i.e., particles with an aerodynamic diameter of $<100 \mathrm{~nm}$ ) have higher toxicity per unit mass (Donaldson et al., 1998; Li et al., 2003; Nel et al., 2006; Oberdörster et al., 2002), have higher deposition efficiencies in the lung (Venkataraman, 1999), and penetrate deeper into the alveolar regions of lungs (Sioutas et al., 2005). Additionally, several studies have also found that PM number concentrations (mostly UFPs) can be associated with adverse effects on human health, particularly for cardiovascular diseases (Delfino et al., 2005; Peters et al., 1997; Wichmann et al., 2000).

Regulations on PM number concentrations have already been implemented on motor vehicle emissions in a few countries. For instance, the Euro 5b and 6 regulations have set a limit to particle number emission factors, in addition to particle mass emission limits, for heavy-duty and gasoline vehicles (http://www.dieselnet.com/standards/eu/ld.php, last access: 20 October 2015). It is also expected that this approach will gradually be adopted in other parts of the world (Friend et al., 2013), based mainly on the critical health implications of the PM number concentrations, especially in smaller fractions like UFPs. This emphasizes the necessity of identification and quantification of PM sources based on number as well as mass (Friend et al., 2013). This allows for sourcespecific assessment of health effects of exposure to PM to provide us with the knowledge required to develop efficient control strategies for PM emissions from major sources to minimize these health effects (Yue et al., 2008).

Positive matrix factorization (PMF) is one of the most widely used receptor models that have been successfully applied to identify and quantify sources of atmospheric particles. The vast majority of previous efforts has been devoted to the identification of sources that contribute to the mass of particles using PMF on chemically speciated PM mass data in different parts of the world (Sowlat et al., 2013, 2012; Dutton et al., 2010; Lim et al., 2010; Alleman et al., 2010; Sofowote et al., 2015). Recently, attempts have been made to characterize sources that contribute to particle number, rather than mass, using PMF applied to particle number size distribution data. These studies have adopted different approaches in their source apportionment, including (1) using particle number size distribution together with gaseous pollutants, chemical composition, meteorological, or traffic data in the PMF analysis (Beddows et al., 2015; Harrison et al., 2011;
Kasumba et al., 2009; Ogulei et al., 2007, 2006b; Thimmaiah et al., 2009; Zhou et al., 2005); (2) using particle number size distribution and chemical composition data in separate and/or combined PMF runs (Beddows et al., 2015; Gu et al., 2011); (3) comparing PMF results with actual events during the study period (Ogulei et al., 2007); and (4) simply correlating the PMF results with gaseous pollutants data (Friend et al., 2013, 2012; Kim et al., 2004). It is noteworthy that the major factors resolved by these studies have been nucleation, traffic, secondary aerosol, urban background, and wood burning.

Numerous studies have been performed in Los Angeles evaluating PM number concentrations as well as size distributions, with a focus on vehicular emissions as a major source of particle number in urban areas (Singh et al., 2006; Zhang et al., 2005). Source apportionment of atmospheric particles has also been extensively studied in Los Angeles, but almost all of the studies have focused on the contribution of different sources to PM mass rather than PM number concentration (Ham and Kleeman, 2011; Hasheminassab et al., 2013; Hwang and Hopke, 2006; Kim and Hopke, 2007; Kim et al., 2010; Schauer and Cass, 2000). To the best of our knowledge, no source apportionment studies have ever been performed in Los Angeles on particle number size distributions using PMF. The only study providing a source apportionment of particle number concentrations in Los Angeles is that of Brines et al. (2015), in which major sources contributing to particle number concentrations were identified in five high-insolation cities around the world (Barcelona, Madrid, Rome, Los Angeles, and Brisbane) using the $k$ means clustering method. It should, however, be noted that, in case of Los Angeles, the Brines et al. (2015) study used particle number size distribution data for a rather limited time period (i.e., 3 months); moreover, the studied size distributions ranged from 13 to $400 \mathrm{~nm}$, thus excluding potentially important PM sources contributing to the larger size fractions of $\mathrm{PM}_{2.5}$ and/or $\mathrm{PM}_{10}$.

In the present work, we collected high-resolution ( $5 \mathrm{~min}$ measurements), wide-spectrum particle number size distribution data (i.e., $13 \mathrm{~nm}$ to $10 \mu \mathrm{m}$, covering the nucleation, Aitken, accumulation, and coarse PM modes) over a long period of time (i.e., 9 months, covering both warm and cold seasons) in a location near downtown Los Angeles, California, to identify and quantify sources contributing to particle number concentrations using the most recent version of the PMF model (version 5.0). We also included gaseous pollutants (i.e., $\left.\mathrm{CO}, \mathrm{NO}, \mathrm{NO}_{2}, \mathrm{O}_{3}\right)$, particle mass $\left(\mathrm{PM}_{10-2.5}\right.$ and $\mathrm{PM}_{2.5}$ ), meteorological (temperature, relative humidity $(\mathrm{RH})$, and wind speed), black carbon (BC), elemental carbon (EC) as well as primary (POC) and secondary organic carbon (SOC), and traffic (counts of light-duty vehicles (LDVs) and heavy-duty vehicles (HDVs)) data as inputs to help identify the factors resolved by the model. Results from the present study can be used as a platform for future health effect studies to estimate the source-specific impact of exposure to PM 
from a number concentration perspective, which is critical for the development and establishment of abatement strategies and standards in order to minimize the most relevant health outcomes.

\section{Methodology}

\subsection{Sampling site}

Continuous measurements were carried out at the particle instrumentation unit (PIU) located on the University of Southern California's (USC) park campus, approximately $3 \mathrm{~km}$ south of downtown Los Angeles, CA. The PIU is located within approximately $150 \mathrm{~m}$ downwind of a routinely congested interstate freeway, i.e., I-110, and is also in close proximity to parking and construction facilities. Previous studies conducted by this research group have indicated that the PIU is a mixed urban site that is also heavily impacted by vehicular emissions (Geller et al., 2004; Moore et al., 2007; Hasheminassab et al., 2014b).

\subsection{Sampling time, method, and instrumentation}

Continuous measurements were conducted at the PIU from August 2014 through March 2015 as well as in August 2015. To obtain number size distribution of atmospheric particles in the size range of 14-760 nm (mobility diameter), a scanning mobility particle sizer (SMPS ${ }^{\mathrm{TM}}$, TSI Model 3081) was used, which was connected to a condensation particle counter (CPC, model 3020, TSI Inc., USA). Particles in the size range of $0.3-10 \mu \mathrm{m}$ (optical diameter) were measured using an Optical Particle Sizer (OPS ${ }^{\text {TM }}$, Model 3330, TSI Inc., USA). The time resolution for these two instruments was $5 \mathrm{~min}$. The OPS instrument was calibrated by the manufacturer using polystyrene latex (PSL) particles, which have a dynamic shape factor of 1 (i.e., spherical particles) and a refractive index of 1.59. It should also be noted that the measurements provided by the OPS instrument depend primarily on the refractive index and the dynamic shape factor (Hasheminassab et al., 2014b). Numerous studies have indicated that for spherical particles, the size selection offered by optical particle counters, such as the OPS instrument, is quite similar to the actual physical diameter of the particle being measured (Chen et al., 2011; Hasheminassab et al., 2014b; Hering and McMurry, 1991; Reid et al., 1994). That said, there is compelling evidence in the literature supporting the fact that the refractive index and the dynamic shape factor for ambient aerosols in urban areas (such as Los Angeles) are quite similar to those of PSL particles (Covert et al., 1990; Ebert et al., 2004; Hänel, 1968; Kent et al., 1983; Stolzenburg et al., 1998; Strawa et al., 2006; Watson et al., 2002). To further evaluate this assumption, we used the Multi-Instrument Manager $\left(\mathrm{MIM}^{\mathrm{TM}}\right)$ software, developed by TSI Inc., USA, which estimates the refractive index and dynamic shape factor of aerosols from parallel SMPS and OPS scans. The output from this software indicated that the average real part of the refractive index for the aerosols collected in this study was $1.59 \pm 0.01$ and their dynamic shape factor was $0.99 \pm 0.02$. This finding is also in concert with the results of Hasheminassab et al. (2014b), which reported an average shape factor of near unity at the same sampling site, using the apparent and material density of aerosols. Hence, further adjustment of OPS sizing was deemed unnecessary and the OPS size distribution, with the original size selection, was merged with the SMPS size spectra. Therefore, size bins covering the range of $13.6-514 \mathrm{~nm}$ from SMPS (without subsequent combination into larger size fractions) were merged with the OPS channels from 0.522 to $9.01 \mu \mathrm{m}$ as the input data to the PMF model. More detailed information on the sensitivity of the OPS sizing to the refractive index and the dynamic shape factor of aerosols can be found in Hasheminassab et al. (2014b).

Black carbon (BC) concentrations, with a time resolution of $15 \mathrm{~min}$, were measured using a portable Aethalometer (Magee Scientific, model AE-42). Hourly concentrations of elemental carbon (EC) and organic carbon (OC) were measured using a semicontinuous EC/OC carbon aerosol analyzer (Model 4, Sunset Laboratory Inc., USA), using the thermal/optical transmittance measurement protocol of the National Institute of Occupational Safety and Health (NIOSH 5040). By applying the EC tracer method, Saffari et al. (2016) estimated the primary organic carbon (POC) and secondary organic carbon (SOC) concentrations from total $\mathrm{OC}$ at the same location. These two parameters (i.e., POC and SOC) were also used as input parameters in the PMF model, as they can provide valuable input regarding the detection of primary and secondary sources of PM. The EC tracer method has been discussed in detail elsewhere (Day et al., 2015; Saffari et al., 2016). Briefly, the main assumption in this method is that EC and POC are released from similar sources; therefore, this approach is most applicable where combustion is the main source of ambient POC (Day et al., 2015). It is noteworthy that, in the present study, the sampling site was located in close proximity to a major freeway, thereby making the EC tracer suitable for the data collected in this location, as it has also been used in previous studies in the same sampling site (Polidori et al., 2007; Saffari et al., 2016) as well as similar locations in the Los Angeles basin (Na et al., 2004; Strader et al., 1999). In this method, the following equations can be used after determining the ratio of POC to EC to estimate the concentration of SOC:

$\mathrm{POC}=[\mathrm{OC} / \mathrm{EC}]_{p} \times \mathrm{EC}+b$

$\mathrm{SOC}=\mathrm{OC}-\mathrm{POC}$,

where $[\mathrm{OC} / \mathrm{EC}]_{p}$ is the $\mathrm{POC}$ to $\mathrm{EC}$ ratio; $b$ is the intercept of the linear regression between POC and EC, which is considered to be the portion of POC associated with noncombustion emissions. Using Eq. (1), the slope and the intercept of the regression line were found to be $1.55( \pm 0.07)$ and 
$0.45( \pm 0.24)$, respectively. More detailed information on the results obtained using the EC tracer method can be found elsewhere (Saffari et al., 2016). It is also noteworthy that we used the high EC edge method to determine observations with a high probability of dominant POC contribution, which is believed to be a more accurate method for the identification of the $[\mathrm{OC} / \mathrm{EC}]_{p}$ ratio compared to the traditional approach, as discussed by Day et al. (2015), and has also been successfully applied in a number of previous studies (Harrison and Yin, 2008; Lim and Turpin, 2002; Na et al., 2004).

\subsection{Auxiliary variables}

To help better identify the factors resolved by the PMF model, additional parameters, including gaseous pollutants (i.e., $\mathrm{CO}, \mathrm{NO}, \mathrm{NO}_{2}$, and $\mathrm{O}_{3}$ ) and particulate matter mass concentrations in two size fractions (i.e., $\mathrm{PM}_{10-2.5}$ and $\mathrm{PM}_{2.5}$ ), meteorological parameters (i.e., temperature, relative humidity, and wind speed), and traffic flow data (counts of LDVs and HDVs), were also included in the model as auxiliary variables. Hourly concentrations of particulate mass and gaseous pollutants together with hourly measurements of meteorological parameters were acquired from the online database of the California Air Resources Board (CARB), for the sampling site located in downtown Los Angeles (North Main St.), approximately $3 \mathrm{~km}$ to the northeast of the PIU. The hourly traffic flow data were acquired from the nearest vehicle detection station (VDS) to our sampling site on the freeway I-110, operated by the freeway performance measurement system (PeMS), under the California Department of Transportation (CalTrans). Table 1 provides a summary of statistics of the input parameters to the PMF model in this study. To achieve the same time resolution across all variables, we calculated hourly averaged data points for all variables.

\subsection{Meteorology in central Los Angeles}

To evaluate the impact of meteorological conditions on factor contributions as well as to better identify the resolved factors based on their expected seasonal trends, the study period was partitioned into two phases, i.e., colder phase (from November to February) and warmer phase (from August to October as well as March), and the model outputs, except for factor profiles, are presented for each phase accordingly. Figure 1 illustrates the diurnal variation of important meteorological parameters, namely, temperature, $\mathrm{RH}$, wind speed, and solar radiation, in the cold and warm phases. As can be seen from the figure, on average, the temperature was $5-7^{\circ} \mathrm{C}$ higher in the warm phase than in the cold phase, although the trends were similar in both phases. Minimum temperatures were observed in the early morning (coinciding with morning rush hours), while maximum temperatures were seen at around noon. Conversely, RH peaked at night and exhibited a minimum in the early afternoon. RH was also slightly higher in
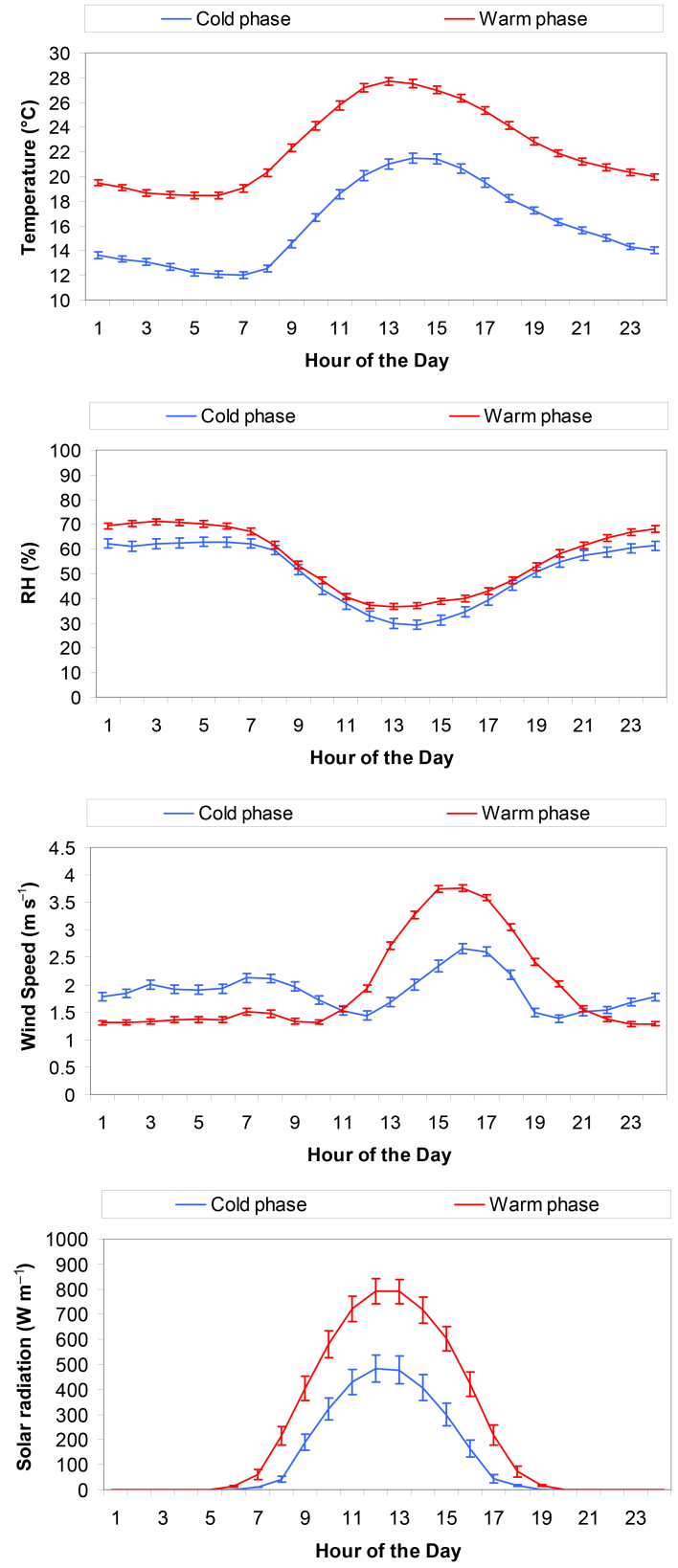

Figure 1. Diurnal variations of important meteorological parameters in the cold and warm phases. Error bars correspond to 1 standard error.

the warm phase than in the cold phase. As expected, wind speed peaked in the early afternoon during the warm phase and slightly shifted to the evening in the cold phase, while the slowest winds blew during nighttime. The wind speeds were also higher in the warm phase compared to the cold phase. Solar radiation had a consistent trend in both phases, peaking at noon, with the levels being higher in the warm phase than in the cold phase, as one would expect. Similar trends and levels were also observed by Hasheminassab et al. (2014b) in central LA, indicating the occurrence of stable 
Table 1. Summary of the input parameters to the PMF model in this study.

\begin{tabular}{lll}
\hline Parameter & Source of data & Time resolution in original data set \\
\hline EC, OC & Sunset monitor & $1 \mathrm{~h}$ \\
Size distribution $(14-760 \mathrm{~nm})$ & SMPS & $5 \mathrm{~min}$ \\
Size distribution $(0.3-10 \mu \mathrm{m})$ & OPS & $5 \mathrm{~min}$ \\
$\mathrm{BC}$ & Aethalometer & $15 \mathrm{~min}$ \\
PM mass concentration data $\left(\mathrm{PM}_{10-2.5}, \mathrm{PM}_{2.5}\right)$ & $\mathrm{CARB}$ & $1 \mathrm{~h}$ \\
Gaseous pollutants $\left(\mathrm{NO}, \mathrm{NO}_{2}, \mathrm{CO}, \mathrm{O}_{3}, \mathrm{SO}_{2}\right)$ & CARB & $1 \mathrm{~h}$ \\
Meteorological data $\left(T, \mathrm{RH}_{\text {, wind speed }(\mathrm{WS}))}\right.$ & $\mathrm{CARB}$ & $1 \mathrm{~h}$ \\
Traffic data (counts of LDVs and $\mathrm{HDV})$ & PeMS & $1 \mathrm{~h}$ \\
\hline
\end{tabular}

atmospheric conditions during nighttime until morning rush hours, especially in colder months of the year.

\subsection{PMF model}

PMF, first developed by Paatero and Tapper (1993), is a multivariate statistical model used for identifying and quantifying the contribution of different sources to a set of samples using the fingerprints of those sources. This multivariate factor analysis tool decomposes a matrix of speciated data into two submatrices, i.e., factor profiles and source contributions, as shown below (Krecl et al., 2008):

$\mathbf{X}=\mathbf{G} \cdot \mathbf{F}+\mathbf{E}$,

where $\mathbf{X}$ is the matrix of samples (here, particle number size distribution together with auxiliary variables data); $\mathbf{G}$ is the matrix containing source contributions; $\mathbf{F}$ is the matrix containing factor profiles; and $\mathbf{E}$ is the residual matrix.

The above equation can also be expressed mathematically, as the following (Norris et al., 2014):

$x_{i j}=\sum_{k=1}^{p} g_{i k} f_{k j}+e_{i j}$,

where $x_{i j}$ is the PM number concentration (or concentration of another auxiliary species) for the $i$ th sample and the $j$ th size bin (or species); $p$ is the number of factors that contribute to the PM number concentrations; $g_{i k}$ is the relative contribution of $k$ th factor to $i$ th sample; $f_{i k}$ is the PM number concentration of $j$ th size bin in the $k$ th factor; and $e_{i j}$ is the residual (observed-estimated) value for the $i$ th sample and $j$ th size bin.

With the constraint that no sample can have a significantly negative contribution, and using a least-squares method, the PMF then resolves factor profiles and contributions by attempting to minimize the $Q$ value, as shown below (Paatero, 1997; Paatero and Tapper, 1994):

$Q=\sum_{i=1}^{n} \sum_{j=1}^{m}\left[\frac{x_{i j}-\sum_{k=1}^{p} g_{i k} \cdot f_{k j}}{u_{i j}}\right]^{2}$, where $u_{i j}$ is the uncertainty associated with the sample $x_{i j}$.

One of the advantages of the PMF model is weighting every single value in the input data matrix using user-provided uncertainties, enabling the model to allow for measurement confidence in resolving the factor profiles and contributions (Paatero et al., 2014). In the present work, since no measurement uncertainties were available for the input parameters, we applied the method suggested by Ogulei et al. (2006a, b) and Zhou et al. (2004) to calculate the uncertainties for individual data points inserted into the model. For this purpose, measurement errors were first estimated for each data point using the following equation:

$\sigma_{i j}=C_{1}\left(N_{i j}+\overline{N_{j}}\right)$,

where $\sigma_{i j}$ is the estimated measurement error for the $i$ th sample and $j$ th size bin (or concentration of auxiliary variables); $C_{1}$ is an empirical constant usually between 0.01 and 0.05 ; $N_{i j}$ is the observed number concentration for the $i$ th sample and $j$ th size bin (or concentration of auxiliary variables); and $\bar{N}_{j}$ is the arithmetic mean of the PM number concentrations for the $j$ th size bin (or concentration of auxiliary variables).

The value of the measurement method obtained from the above equation is then used to calculate the measurement uncertainty, according to the following equation:

$S_{i j}=\sigma_{i j}+C_{2} \max \left(\left|x_{i j}\right|,\left|y_{i j}\right|\right)$,

where $S_{i j}$ is the calculated uncertainty associated with the $i$ th sample and $j$ th size bin; $C_{2}$ is an empirical constant usually between 0.1 and 0.5 ; and $Y_{i j}$ is the value calculated by the model for $x_{i j}$. In the present work, $C_{1}$ and $C_{2}$ values of 0.05 and 0.1 were chosen to obtain the most physically interpretable solution using a trial and error approach.

In the present study, the most recent version of the PMF model, version 5.0, newly released by the United States Environmental Protection Agency (PMF guide), was used. Uncertainties associated with the resolved factor profiles were estimated using three error estimation methods, namely, displacement (DISP) analysis, bootstraps (BS) method, and a combination of DISP and BS methods (BS-DISP). For the DISP analysis, a solution was considered valid if the observed drop in the $Q$ value was below $0.1 \%$ and there were 
Table 2. Summary statistics for the parameters included in the PMF model.

\begin{tabular}{|c|c|c|c|c|c|}
\hline Species & Geometric mean & Standard error & Min & Max & $S / N$ ratio \\
\hline Total number concentration (particle $\mathrm{cm}^{-3}$ ) & 6860.00 & 94.10 & 524.00 & 32400.00 & 7.00 \\
\hline $\mathrm{PM}_{10-2.5}\left(\mu \mathrm{g} \mathrm{m}^{-3}\right)$ & 15.90 & 0.19 & 2.00 & 77.00 & 7.00 \\
\hline $\mathrm{PM}_{2.5}\left(\mu \mathrm{g} \mathrm{m}^{-3}\right)$ & 14.50 & 0.23 & 1.00 & 101.00 & 6.90 \\
\hline $\mathrm{CO}(\mathrm{ppm})$ & 0.58 & 0.01 & 0.10 & 2.19 & 7.10 \\
\hline NO (ppb) & 8.46 & 0.57 & 1.00 & 212.00 & 5.80 \\
\hline $\mathrm{NO}_{2}(\mathrm{ppb})$ & 22.50 & 0.23 & 1.90 & 75.00 & 7.10 \\
\hline $\mathrm{O}_{3}(\mathrm{ppb})$ & 17.40 & 0.33 & 2.00 & 105.00 & 6.80 \\
\hline $\mathrm{BC}\left(\mu \mathrm{g} \mathrm{m}^{-3}\right)$ & 1.14 & 0.02 & 0.124 & 9.13 & 6.90 \\
\hline $\mathrm{POC}^{*}\left(\mu \mathrm{g} \mathrm{m}^{-3}\right)$ & 2.20 & 0.08 & 0.10 & 19.20 & 6.80 \\
\hline $\mathrm{SOC}^{*}\left(\mu \mathrm{g} \mathrm{m}^{-3}\right)$ & 2.13 & 0.05 & 0.04 & 16.30 & 7.10 \\
\hline $\mathrm{EC}^{*}\left(\mu \mathrm{g} \mathrm{m}^{-3}\right)$ & 1.01 & 0.03 & 0.01 & 7.34 & 8.80 \\
\hline $\mathrm{RH}(\%)$ & 50.40 & 0.40 & 6.00 & 99.00 & 7.10 \\
\hline Temperature $\left({ }^{\circ} \mathrm{C}\right)$ & 18.80 & 0.13 & 3.89 & 38.33 & 7.30 \\
\hline Wind speed $\left(\mathrm{WS} ; \mathrm{m} \mathrm{s}^{-1}\right)$ & 4.03 & 0.04 & 1.00 & 14.00 & 6.80 \\
\hline LDVs $\left(\right.$ no. $\left.\mathrm{h}^{-1}\right)$ & 3790 & 34 & 691 & 7620 & 7.10 \\
\hline HDVs (no. $\left.\mathrm{h}^{-1}\right)$ & 153 & 3 & 5 & 920 & 6.80 \\
\hline
\end{tabular}

* Values pertain to the runs including EC/OC data.

no factor swaps for the smallest $\mathrm{d} Q_{\max }$ (i.e., 4). For the BS method, 100 runs were selected and a solution was considered valid if all of the factors had a mapping of above $90 \%$. For the BS-DISP analysis, a solution was considered valid if the observed drop in the $Q$ value was below $0.5 \%$ (Brown et al., 2015; Paatero et al., 2014).

The PMF model was run in the robust mode, which downweights the effect of values with high uncertainties (i.e., values set as weak in the model) on the final solution resolved by the model (Brown et al., 2015). Missing values were replaced by interpolating the previous and the next data points in the matrix; however, to decrease the effect of these replaced values on the final solution, their uncertainty was set as 3 times the mean uncertainty for that species (that is practically what the model does to set a species as weak). Based on the recommendations presented by Brown et al. (2015), genuine zero values were included in the input matrix. Particle number concentration (PNC) was selected as the total variable, and the PMF model automatically turned it into a weak species by increasing its uncertainty by a factor of 3 . An extra model uncertainty of $5 \%$ was also set to account for errors that are not covered in the input uncertainty values (Reff et al., 2007), since the uncertainty matrix only includes the effect of random as well as experimental errors.

\subsection{Input matrices}

The model was run in two different scenarios, one with EC/OC data, which included 1053 samples of 131 species, and one without EC/OC data, which included 2976 samples of 129 species. This was due mainly to the fact that the EC/OC data were being collected in parallel for a different study that coincided with the current work in a span of time shorter than the entire study period. Therefore, in order to keep the large number of samples from the main study (i.e., 2976) as well as to use the critical advantage of having $\mathrm{EC} / \mathrm{OC}$ data in the factor identification process, it was decided to run the PMF model in two different scenarios, one including EC/OC data and one without these data. It should also be noted that although the latter matrix contained BC data, this variable was excluded from the former matrix to avoid double counting, as EC was already included in the data set. The results of the PMF run including the EC/OC data are provided in the supplementary information (Fig. S1 in the Supplement).

\section{Results and discussion}

\subsection{Overview of the data}

Table 2 presents the statistical characteristics of the species included in the PMF model. In this table, signal-to-noise $(S / N)$ ratio is a parameter that indicates if the variability in the measurements is real or within the data noise. In the current version of the model, i.e., PMF 5.0, the method used for calculating the $S / N$ ratio has been updated compared to the previous versions, resolving the disadvantages associated with the previous method of $S / N$ calculation (for a more detailed discussion on the $S / N$ calculation methods, see the Supplement). In the current method, if the resulting $S / N$ ratio is above 1, it can be concluded that the species has a reliable signal. As reported in Table 2, all the species in the input matrix had $S / N$ ratios well above 1, indicating very strong signals for all the variables. Figure $\mathrm{S} 2$ also illustrates the correlation between the measured and PMF-predicted to- 
tal number concentrations for the entire sampling period. As can be seen in the figure, the high correlation between measured and predicted values $\left(R^{2}=0.99\right)$ and the slope of the regression line that is very close to 1 indicate that the PMF model has been successful in modeling the input data and apportioning the total PM number concentrations to the resolved factors.

Figure 2 depicts the average number and volume size distributions of all the input data to the PMF model by phase, which were collected during the entire study period. As shown in the figure, the vast majority of the particles were smaller than $100 \mathrm{~nm}$, and the number concentration had a mode diameter of around $40 \mathrm{~nm}$. Additionally, a significantly higher number concentration was observed in the cold phase compared to the warm phase, which is consistent with the results from the previous studies conducted in Los Angeles (Hudda et al., 2010; Singh et al., 2006). Regarding volume concentrations, we observed one minor volume mode in the size range of $300-500 \mathrm{~nm}$ and a major mode at around 4$6 \mu \mathrm{m}$. In this case, the volume concentration was higher in the cold phase than in the warm phase for the minor mode diameter (at 300-500 nm), while a sharper peak was observed for the major mode diameter (at around 4-6 $\mu \mathrm{m}$ ) in the warm phase compared to the cold phase. This PM volume size distribution is typical of urban areas (Vu et al., 2015), and is also consistent with the findings of a previous study conducted recently by this research group at the same sampling location (Hasheminassab et al., 2014b).

\subsection{Number of factors}

In the present work, the PMF model was run several times using different number of factors, input uncertainty matrices (as noted in the methods section), and extra modeling uncertainties to obtain the best and most physically applicable solution. Additionally, we used several criteria to determine the best solution resolved by the model, including (1) particle number size distribution profiles for different factors; (2) volume size distribution profiles for the resolved factors; (3) profiles of auxiliary variables for different factors; (4) contribution of each factor in different seasons to the total number concentrations; (5) diurnal variations of each of the resolved factors in the cold and warm phases; (6) diurnal variations of each of the resolved factors in weekdays versus weekends; and (7) correlation between auxiliary variables and the relative contribution of each of the resolved factors. The sixfactor solution was found to present the most physically explainable one, and was, therefore, chosen as the final solution. When the model was run with one fewer factor (i.e., five-factor solution), the model could not distinguish the two traffic factors, and traffic 1 and traffic 2 factors were merged together. On the other hand, when the model was run with one more factor (i.e., seven-factor solution), a new factor was resolved by the model, with a mode diameter between that of urban background aerosol and secondary aerosol, but without
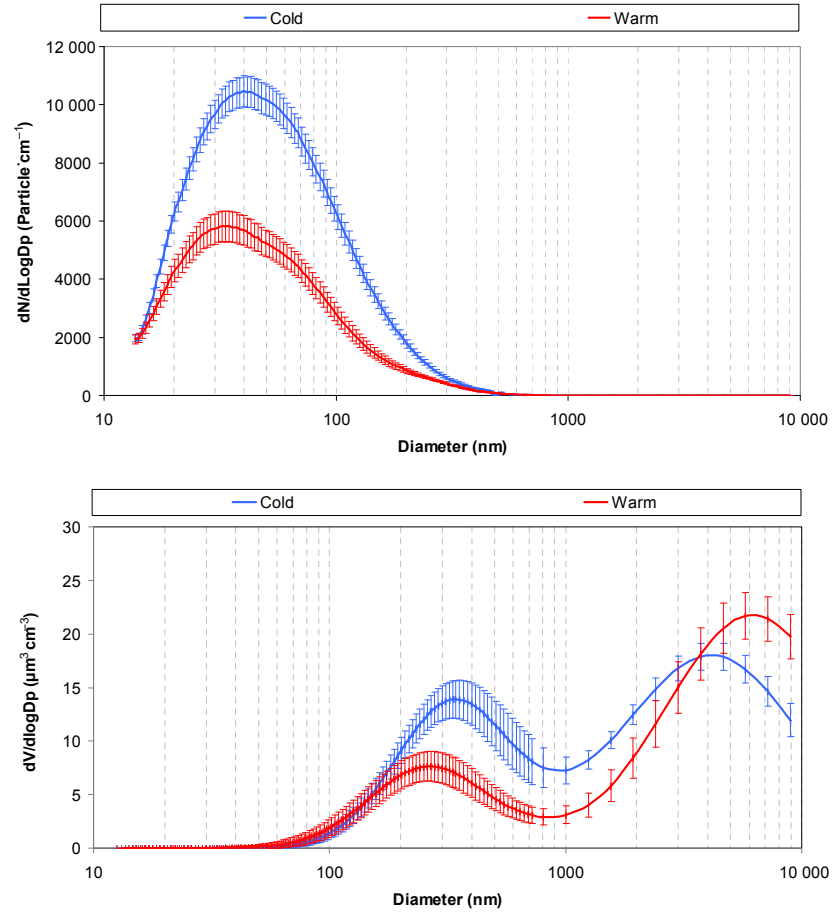

Figure 2. Average number and volume size distributions of all the input samples to the PMF model in the cold and warm phases (the graphs represent geometric means $\pm \mathrm{SE}$ ).

any distinct diurnal, seasonal, or weekday/weekend trends or auxiliary variables profile. Therefore, this factor could not be meaningfully interpreted and identified, prompting us to choose the six-factor as the optimal solution.

Figure 3 illustrates the number size distributions as well as the auxiliary variables profiles for each of the factors resolved by PMF. Figure 4 indicates the volume size distribution of each factor. In Figs. 3, 4, and S1, the black solid lines represent absolute concentrations (number or volume) of each size bin and should be read from the left $y$ axis, while the grey triangles represent the explained variation of each size bin and should be read from the right $y$ axis. The relative contributions (overall, and by cold or warm phases) of each factor to the total number concentrations are shown in Fig. 5. Figure 6 illustrates the contribution (particles $\mathrm{cm}^{-3}$ ) of each of the PMF-resolved factors to the total number concentrations in the cold and warm phases within a box and whisker plot. The diurnal variations and the weekday/weekend trends (geometric means) for each of the factors are illustrated in Figs. 7 and 8, respectively. The Spearman correlation coefficient matrix indicating the association between the auxiliary variables and the factors resolved by the PMF model is also presented in Table 3. 

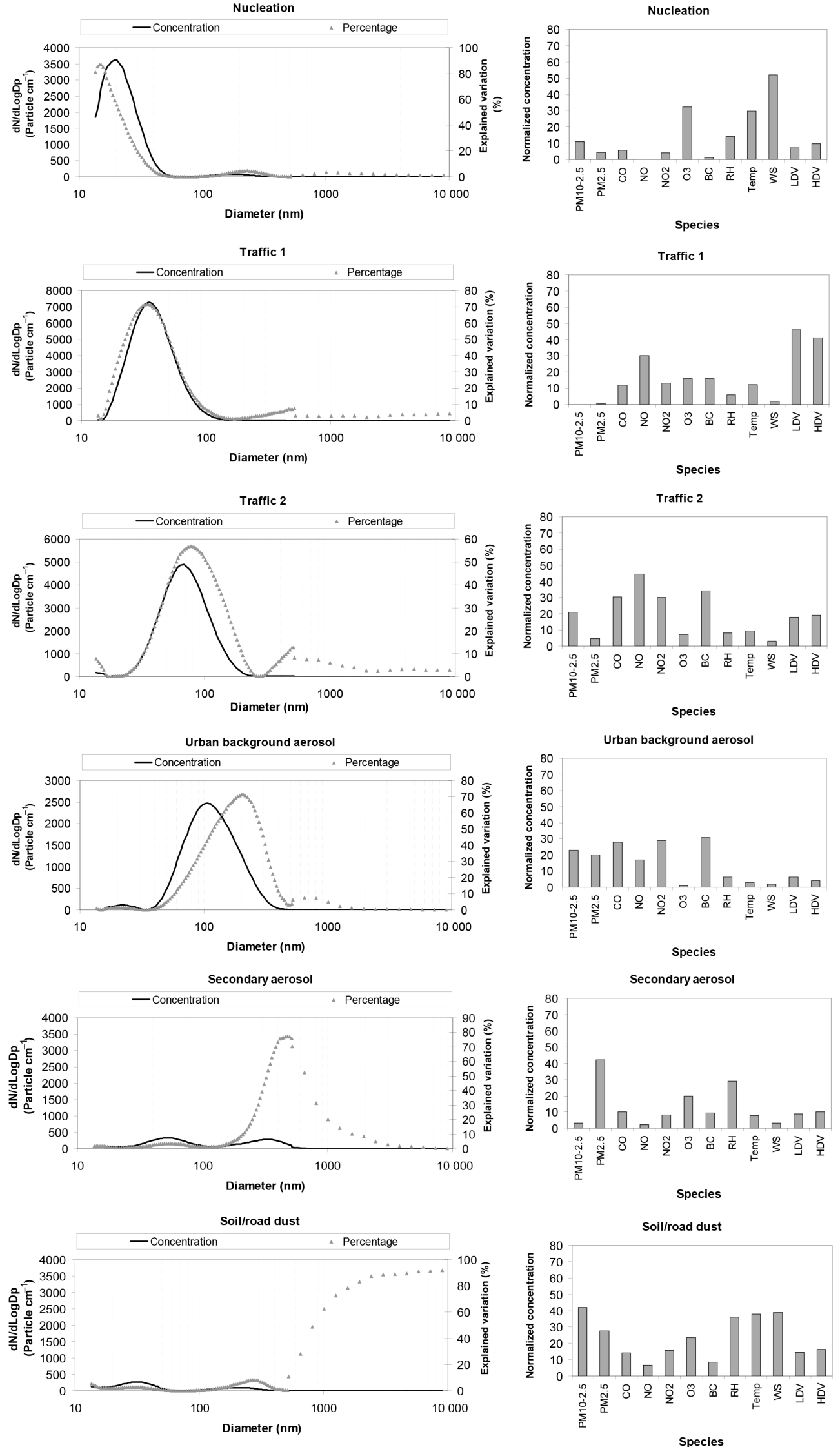

Figure 3. The number size distributions as well as the auxiliary variables profiles for each of the factors resolved by the PMF model. 
Table 3. Spearman correlation coefficient matrix, indicating the association between the auxiliary variables and the factors resolved by the PMF model. $R$ values above 0.5 are in bold.

\begin{tabular}{lrrrrrr}
\hline Species & Nucleation & Traffic 1 & Traffic 2 & Urban background aerosol & Secondary aerosol & Soil/road dust \\
\hline $\mathrm{PM}_{10-2.5}$ & $0.17^{*}$ & $0.21^{*}$ & $0.35^{*}$ & $0.27^{*}$ & $0.09^{*}$ & $0.39^{*}$ \\
$\mathrm{PM}_{2.5}$ & $-0.24^{*}$ & $-0.09^{*}$ & $0.05^{*}$ & $0.33^{*}$ & $0.696 *$ & $0.23^{*}$ \\
$\mathrm{CO}$ & 0.04 & $0.41^{*}$ & $0.58^{*}$ & $0.52^{*}$ & $0.17^{*}$ & $0.28^{*}$ \\
$\mathrm{NO}$ & -0.01 & $0.48^{*}$ & $0.59^{*}$ & $0.57^{*}$ & $0.27^{*}$ & $0.24^{*}$ \\
$\mathrm{NO}_{2}$ & $0.08^{*}$ & $0.50^{*}$ & $0.60^{*}$ & $-0.35^{*}$ & $0.33^{*}$ & $0.14^{*}$ \\
$\mathrm{O}_{3}$ & $0.57^{*}$ & $0.34^{*}$ & $0.40^{*}$ & $0.71^{*}$ & $0.46^{*}$ & $0.19^{*}$ \\
$\mathrm{BC}$ & 0.01 & $0.53^{*}$ & $0.70^{*}$ & $0.30^{*}$ & $0.13^{*}$ & $0.22^{*}$ \\
$\mathrm{POC}$ & $0.09^{*}$ & $0.62^{*}$ & $0.28^{*}$ & $0.58^{*}$ & $0.24^{*}$ & $0.29^{*}$ \\
$\mathrm{SOC}$ & $0.46^{*}$ & $0.12^{*}$ & $0.43^{*}$ & $0.60^{*}$ & $0.46^{*}$ & $0.20^{*}$ \\
$\mathrm{EC}$ & $0.17^{*}$ & $0.47^{*}$ & $0.56^{*}$ & $-0.05^{*}$ & $0.20^{*}$ & $0.17^{*}$ \\
$\mathrm{RH}$ & $-0.26^{*}$ & $-0.32^{*}$ & $-0.30^{*}$ & $-0.39^{*}$ & $0.43^{*}$ & $0.33^{*}$ \\
Temp & $0.52^{*}$ & $-0.23^{*}$ & $-0.18^{*}$ & $-0.04^{*}$ & $0.34^{*}$ & $0.47^{*}$ \\
WS & $0.57^{*}$ & 0.00 & $0.07^{*}$ & $0.05^{*}$ & $-0.25^{*}$ & $0.62^{*}$ \\
LDVs & $0.22^{*}$ & $0.70^{*}$ & $0.42^{*}$ & $-0.08^{*}$ & 0.01 & 0.02 \\
$\mathrm{HDVs}$ & $0.23^{*}$ & 0.52 & $0.43^{*}$ & & $-0.12^{*}$ & -0.01 \\
\hline
\end{tabular}

* Indicates $R$ values that are statistically significant $(P<0.05)$.
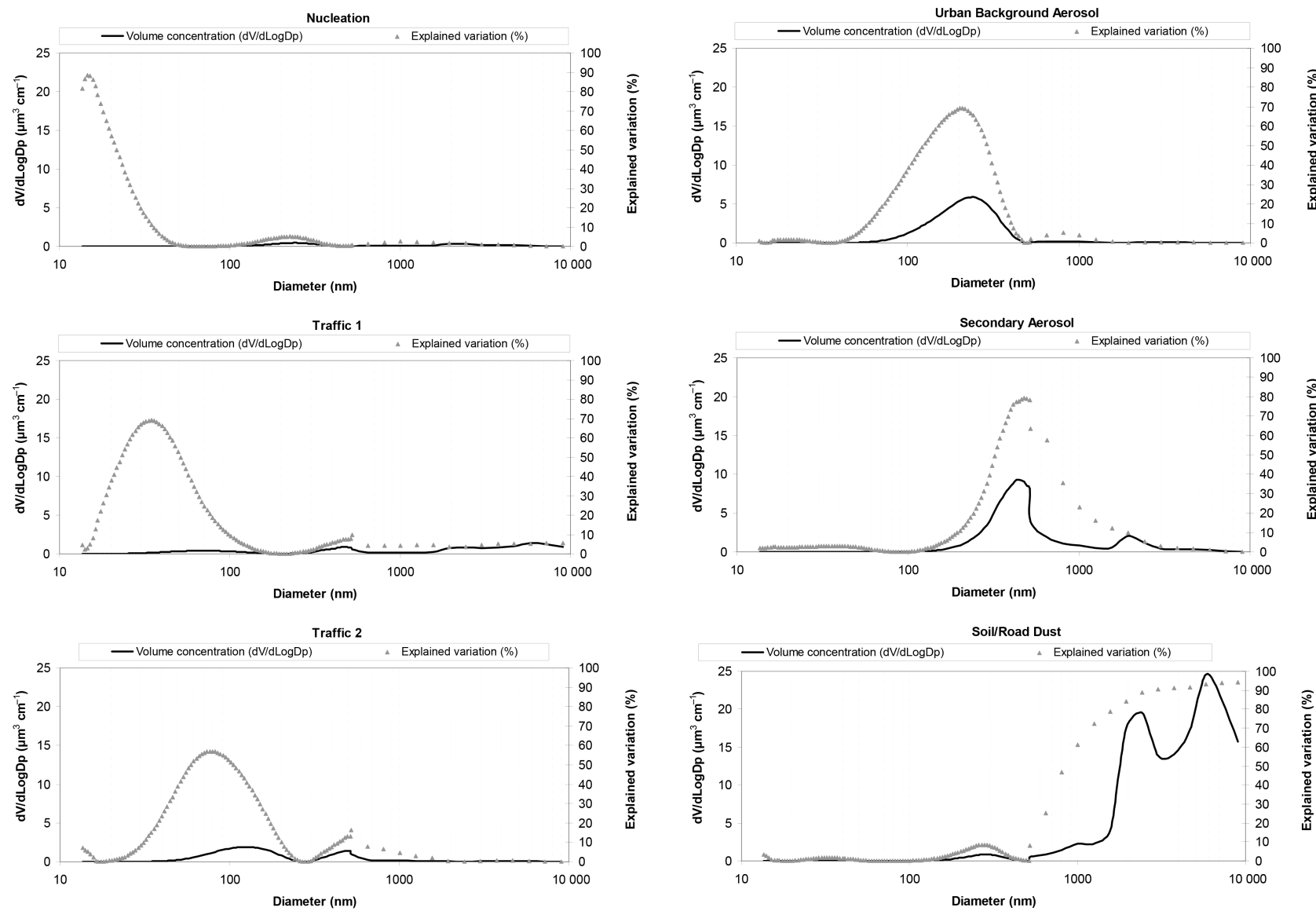

Figure 4. Volume size distributions along with the explained variation (\%) of each factor profile resolved by the PMF model. 
(a)

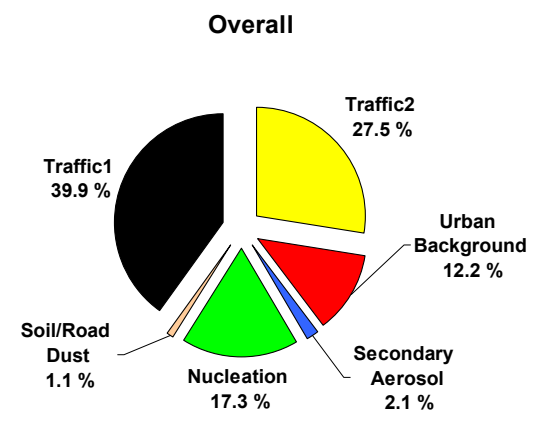

(b)

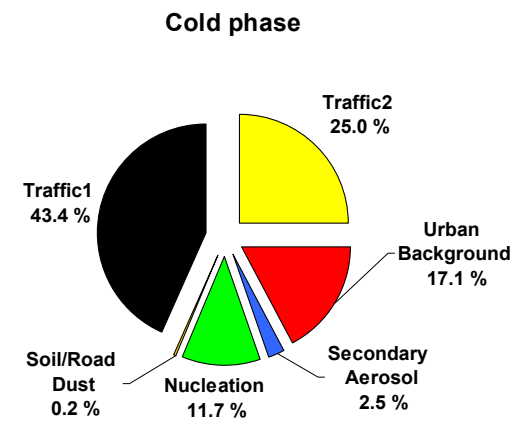

(c)

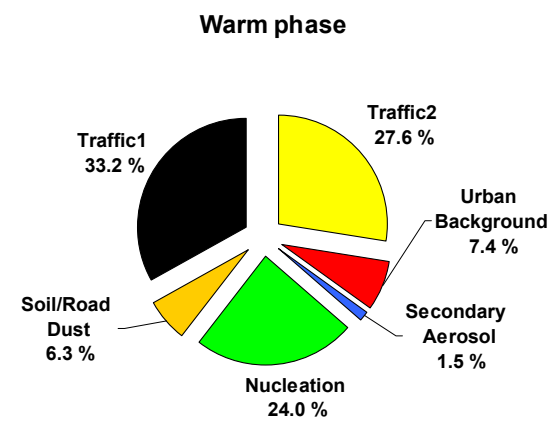

Figure 5. Relative contribution of each factor to the total number concentrations: (a) overall phases; (b) cold phase; and (c) warm phase.

\subsection{Factor identification}

Factor 1: Factor 1 has a number mode at $<20 \mathrm{~nm}$, a volume mode at $<20 \mathrm{~nm}$, and contributes $17.3 \%(11.7-24 \%)$ to the total number concentrations (Figs. 3, 4, and 5). This factor has strong positive (except for RH, with which this factor has negative correlation) associations with temperature, wind speed, SOC, and $\mathrm{O}_{3}$ (Table 3), which are also statistically significant $(p<0.05)$. These associations are also apparent from high loadings of temperature, $\mathrm{RH}$, wind speed, and $\mathrm{O}_{3}$ in the auxiliary variables profile (Figs. 3 and S1). The con-

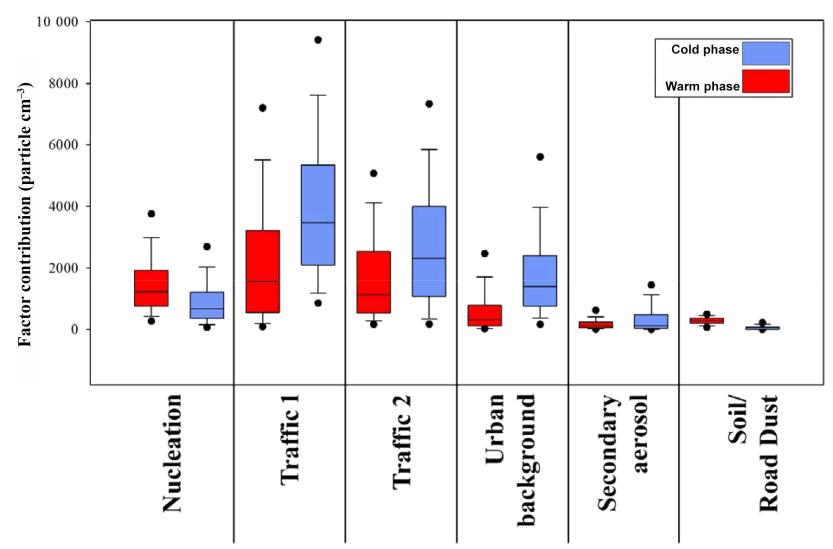

Figure 6. Contribution (particles $\mathrm{cm}^{-3}$ ) of each of the PMFresolved factors to the total number concentrations in the cold and warm phases.

tribution of this factor to the total number concentration was also higher in the warm phase than in the cold phase, when higher temperatures, wind speeds, and solar radiation are observed (Fig. 1); this was the case both in terms of percent contribution $(24 \%$ in the warm phase vs. $11.7 \%$ in the cold phase) and number concentration $\left(589 \pm 25\right.$ particles $\mathrm{cm}^{-3}$ in the cold phase vs. $1153 \pm 28$ particles $\mathrm{cm}^{-3}$ in the warm phase) (Figs. 5 and 6 and Table S1). The diurnal variations for this factor also revealed a sharp peak in the afternoon (14:00-18:00 PT; UTC - 8h) (Fig. 7), which coincides with very high temperatures, wind speeds, and solar radiation as well as with minimum RH (Fig. 1). A minor peak was also observed during morning rush hours (06:00-08:00), which suggests the partial influence from traffic sources, as also observed by loadings of HDVs and LDVs in this factor (Fig. 3). However, there was no significant distinction in the diurnal variation patterns of this factor in weekdays compared to weekends (Fig. 8).

The above characteristics are all typical of a nucleation factor, during which new particles are formed via photochemical events under high temperatures, high wind speeds, and low RH (Beddows et al., 2015; Brines et al., 2015; Dall'Osto et al., 2012; Vu et al., 2015). The minor peak in the early morning can also be explained by the cooling, following dilution, of vehicular exhaust emissions, which leads to the partitioning of semivolatile exhaust gases into the particle phase; this process is further enhanced by the lower temperatures during that time of day (Harrison et al., 2011; Ntziachristos et al., 2007; Janhäll et al., 2004; Charron and Harrison, 2003). Our findings are most specifically consistent with those of the study of Brines et al. (2015), in which the authors had reported nucleation as one of the major sources of UFPs in five high-insolation cities, including Los Angeles, using the data obtained from the same sampling location. They observed very similar diurnal variation for nucleation, with a 

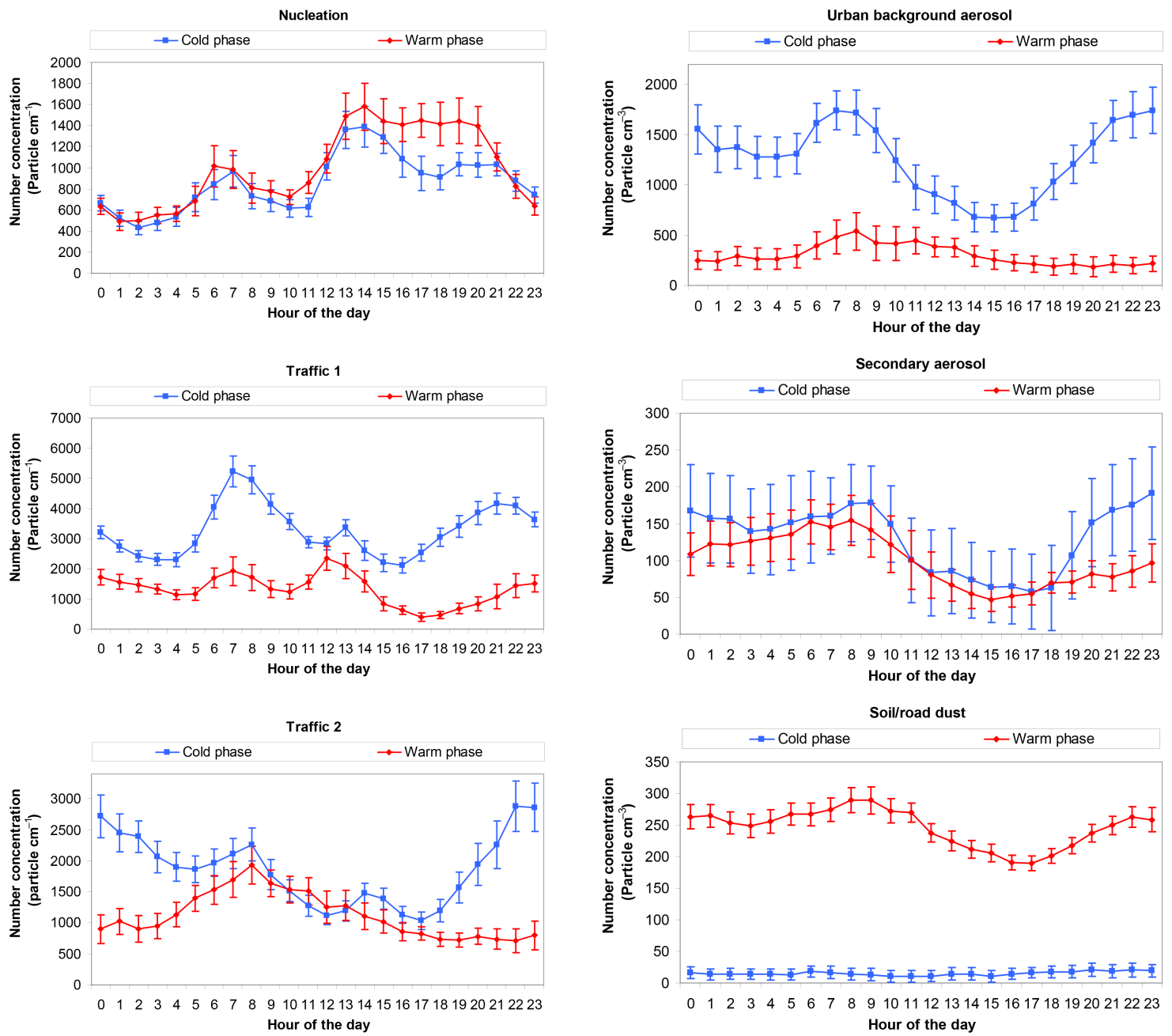

Figure 7. Diurnal variations (geometric means) of number concentrations (particles $\mathrm{cm}^{-3}$ ) from each factor resolved by the PMF model in the cold and warm phases. Error bars correspond to 1 standard error.

minor peak in the early morning and a major peak in the early afternoon at the same sampling location in Los Angeles.

Factor 2: Factor 2 is mostly represented by particles at $20-40 \mathrm{~nm}$ and contributes about $40 \%(33.2-43.4 \%)$ to the total number concentration (Figs. 3 and 5). It also has a volume concentration peak at around $30-40 \mathrm{~nm}$ (Fig. 4). Judging by the loadings presented in the auxiliary variables profile (Fig. 3) and correlation coefficients presented in Table 3, this factor has clear associations with gaseous pollutants (e.g., $\mathrm{CO}, \mathrm{NO}$, and $\mathrm{NO}_{2}$ ), $\mathrm{BC}, \mathrm{EC}$, and $\mathrm{POC}$ (from the scenario containing EC/OC data (Fig. S1), which themselves are indicators of vehicular emissions (Gu et al., 2011; Ogulei et al., 2006b). In addition, high species loadings (Fig. 3) and correlation coefficients (Table 3) of LDV and HDV counts can also be observed for this factor, indicating the influence of nearby passing traffic on this factor. The contribution of this factor to the total number concentration was also much higher in the cold phase than in the warm phase, when lower temperatures, wind speeds, and solar radiation (Fig. 1) lead to increased atmospheric stability and lower mixing height (Hasheminassab et al., 2014a); this was the case both in terms of percent contribution $(43.4 \%$ in the cold phase vs. $33.2 \%$ in the warm phase) and number concentration $\left(3166 \pm 66\right.$ particles $\mathrm{cm}^{-3}$ in the cold phase vs. $1201 \pm 61$ particles $\mathrm{cm}^{-3}$ in the warm phase) (Figs. 5 and 6 and Table S1). The diurnal variations also revealed a distinctive pattern peak in the morning rush hours (around 07:00 08:00) (Fig. 7). The weekday/weekend analysis also indicated that this factor had higher contributions during the weekdays compared to the weekends (Fig. 8). Therefore, this factor can be attributed to traffic tailpipe emissions. Previous source apportionment studies on number size distributions have also associated such characteristics with fresh vehicular emissions (Beddows et al., 2015; Dall'Osto et al., 2012; Vu et al., 2015). This factor is denoted as traffic 1, given that another factor attributed to traffic emissions was resolved, 

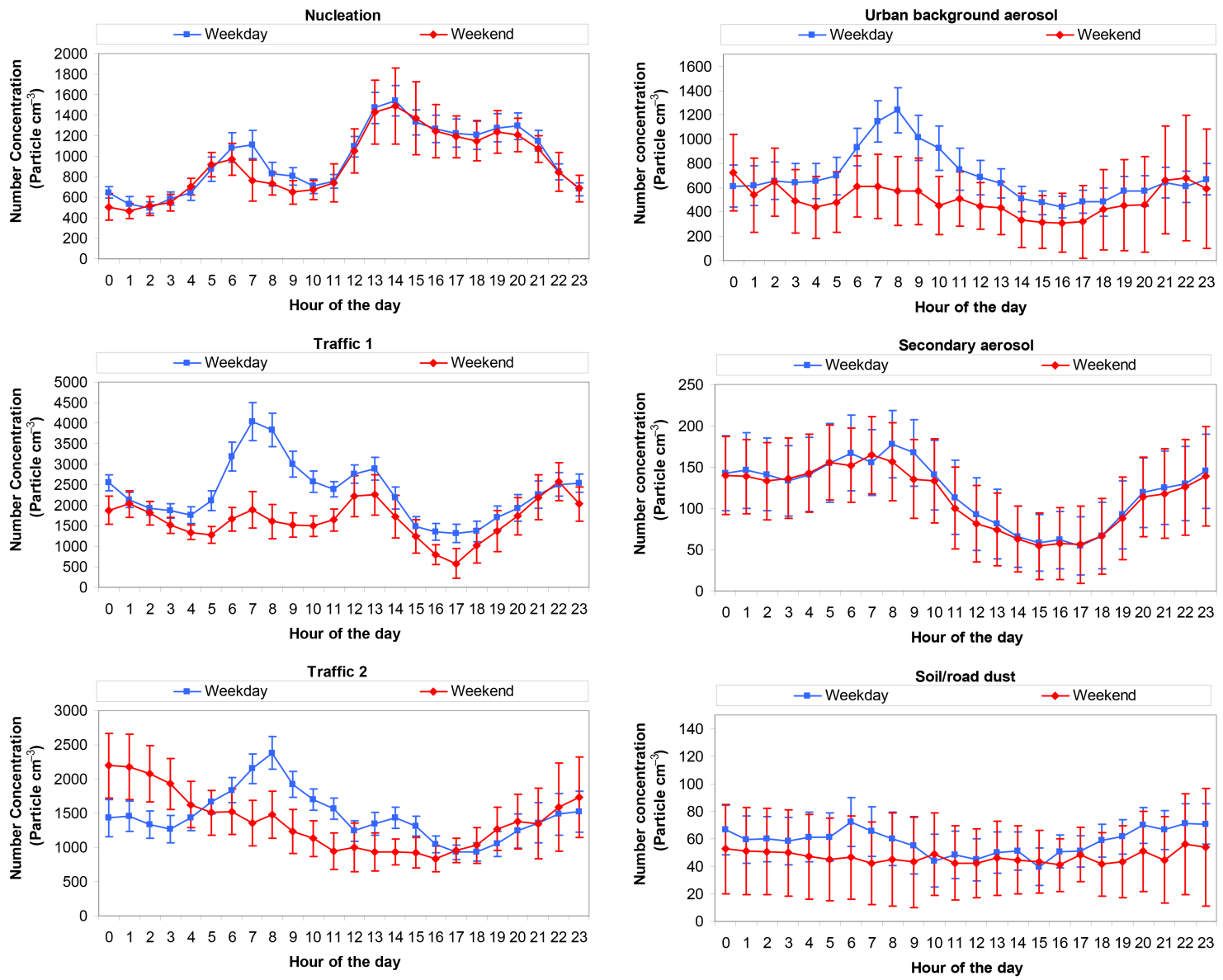

Figure 8. Weekday/weekend analysis of each of the factors resolved by the PMF model (values are geometric means). Error bars correspond to 1 standard error.

which will be discussed in the following section. The characteristics of this traffic factor are in agreement with what Brines et al. (2015) reported for five high-insolation cities, including Los Angeles.

Factor 3: Factor 3 has a major peak in the Aitken mode $(60-100 \mathrm{~nm})$ and contributes $27.5 \%(25-27.6 \%)$ to the total number concentration (Figs. 3 and 5). It also exhibited a volume concentration peak at around $100 \mathrm{~nm}$ (Fig. 4). Judging by the loadings presented in the auxiliary variables profile (Figs. 3 and S1) and correlation coefficients presented in Table 3, significant associations can be observed between this factor and gaseous pollutants (e.g., $\mathrm{CO}, \mathrm{NO}$, and $\mathrm{NO}_{2}$ ), as well as with $\mathrm{BC}$ (and EC from the scenario containing EC/OC data (Fig. S1)). Although weaker than those of Factor 2, there are significant positive associations between this factor and LDV and HDV counts (Fig. 3 and Table 3), suggesting the likely influence of nearby passing traffic. This factor also had a significantly higher contribution to the total number concentrations in the cold phase than in the warm phase (an average of $1755 \pm 56$ particles $\mathrm{cm}^{-3}$ in the cold phase vs. $1059 \pm 43$ particles $\mathrm{cm}^{-3}$ in the warm phase
(Fig. 6)), in spite of the fact that its percent contribution to the total PM number concentrations was comparable in both phases, and slightly higher in the warm phase $(25 \%$ in the cold phase vs. $27.6 \%$ in the warm phase (Fig. 5)). This is due mainly to the fact that the contribution of the traffic 1 factor is so large in the cold phase that it has significantly obscured the percent contribution of other factors in this phase, even though their absolute contributions in terms of total number concentrations were higher in the cold phase.

The diurnal variations for this factor also indicated clear peaks during the morning rush hours (06:00-08:00) in both phases, along with another peak at late night during the cold phase, most likely due to the stagnant atmospheric conditions during this time of the year, which trap the emissions in lower altitudes (Fig. 7). This diurnal profile suggests a major contribution from semivolatile compounds in the atmosphere, particularly in the cold phase, as reflected in the substantial increase at nighttime. The weekday/weekend analysis for this factor revealed larger contributions in weekdays than in weekends, especially during daytime hours. The slightly higher nighttime contribution of this factor at the 
weekends compared to the weekdays can be attributed to the larger number of within-city journeys being made on holiday nights. These levels and trends are, overall, suggestive of emissions from vehicular sources. However, the larger size range of this factor compared to factor 2, combined with the involvement of EC and SOC (as observed from the scenario containing EC/OC data (Fig. S1)) as well as BC, suggest that although this factor also originates from traffic, the particles are older (i.e., more aged) than those observed in factor 2 and are mostly in the Aitken and accumulation modes; therefore, it was labeled as traffic 2 . This finding is also consistent with those of the previous studies (e.g., Brines et al., 2015), in which the authors detected distinct traffic factors (with a collective relative contribution of approximately $60 \%$ in Los Angeles at the same sampling site) using a different source apportionment method, named $k$ means cluster analysis. It should be noted that it is quite common in source apportionment studies performed on size-segregated PM number concentrations to detect more than one traffic factor, due primarily to the fact that particle sizes may change, as particles undergo processes including agglomeration as well as evaporation or condensation of semivolatile species from or onto their surface following their release into the atmosphere (Harrison et al., 2016; Kim et al., 2004; Zhou et al., 2005).

It is also noteworthy that the traffic 2 factor has a slightly higher HDV loading than traffic 1 factor (Figs. 3 and S1). It also has a somewhat stronger positive correlation with HDVs ( $R=0.43)$ than with LDVs $(R=0.41)$, while the traffic 1 factor has a stronger correlation with LDVs $(R=0.69)$ than with HDVs $(R=0.52)$. Additionally, the stronger correlation of traffic 2 factor with $\mathrm{EC}$ and $\mathrm{BC}$ compared to traffic 1 leads us to the hypothesis that HDVs might be contributing more to this factor than LDVs are. Vu et al. (2015) have also suggested that observing a number concentration mode at the size range of $60-100 \mathrm{~nm}$ can be a result of incomplete combustion of diesel fuel, consisting of pyrolytic EC and OC. Other studies have also found two particle modes, or factors, for traffic-related emissions. Although the emissions in both of these two modes are believed to come from the same fleet of vehicles, they have different formation mechanisms and chemistry, with particles associated with the second mode (i.e., soot mode) assumed to have an elemental carbon core. This is consistent with the findings of the present study, judging by the mode diameter and high loading of BC, $\mathrm{EC}$, and $\mathrm{OC}$ in the traffic 2 factor (Figs. 3 and S1) and the strong correlation of this factor with $\mathrm{BC}, \mathrm{EC}$, and $\mathrm{OC}$ (Table 3). Additionally, studies have indicated that a fraction of diesel PM emissions, which is generally in the range of 50$200 \mathrm{~nm}$, comprises particles that have an elemental core, with low-vapor-pressure hydrocarbons and sulfur compounds being adsorbed on their surface (Burtscher, 2005). Therefore, it might be likely that this factor represents a higher contribution of HDV emissions; although stronger evidence is required to confirm this hypothesis.
Factor 4: Factor 4, which contributes $12.2 \%$ (7.4-17.1\%) to the total number concentration, is represented by a number mode at around $220 \mathrm{~nm}$ and a volume mode at around $250 \mathrm{~nm}$ (Figs. 3, 4, and 5). The profile for the auxiliary variables also indicates high loadings for gaseous pollutants (e.g., $\mathrm{CO}, \mathrm{NO}$, and $\mathrm{NO}_{2}$ ) and $\mathrm{BC}$ (Fig. 3) as well as for $\mathrm{EC}$ and SOC (when the PMF model was run with the EC/OC data (Fig. S1)). The large correlation coefficients of this factor with the aforementioned species also confirm its strong association with these parameters (Table 3). The lower-thanunity $\mathrm{NO} / \mathrm{NO}_{2}$ ratio for this factor also suggests that these particles are aged compared to the newly formed particles (Liu et al., 2014). This is also supported by the stronger positive correlation of this factor with SOC than with POC, suggesting the fact that this factor does not come from direct emissions and has most likely undergone processes and reactions in the atmosphere. As can be inferred from Figs. 5 and 6 , the contribution of this factor is significantly higher in the cold phase than in the warm phase, both in terms of percent contribution $(17.1 \%$ in the cold phase vs. $7.4 \%$ in the warm phase) and the absolute contribution to the total number concentration $\left(1200 \pm 41\right.$ particles $\mathrm{cm}^{-3}$ in the cold phase vs. $284 \pm 23$ particles $\mathrm{cm}^{-3}$ in the warm phase). As seen in Fig. 7, the diurnal variations for this factor also exhibit a clear peak during morning hours, which indicates higher concentrations when the atmosphere is more stable and wind speeds are low, especially in the cold phase when these conditions are even more intense (Fig. 1). The weekday/weekend analysis also revealed a slightly elevated contribution of this factor to the total number concentrations during morning rush hours, especially during the weekdays, suggesting the small influence of traffic emissions on this factor. Previous studies have indicated that these are characteristics of the urban background aerosol, as suggested by (Beddows et al., 2015; Dall'Osto et al., 2012).

Factor 5: Factor 5 has a number and volume mode at around $500 \mathrm{~nm}$ and a minor number mode at $50 \mathrm{~nm}$ (looking at the black dots, representing the explained variations) (Figs. 3 and 4). This factor contributes $2.1 \%(1.5-2.5 \%)$ to the total number concentration (Fig. 5). It is also associated with high loadings of $\mathrm{PM}_{2.5}$ mass concentration (i.e., major contributor to $\mathrm{PM}_{2.5}$ mass), $\mathrm{NO}, \mathrm{NO}_{2}$, temperature, $\mathrm{RH}$ (Fig. 3), and SOC (as observed from the scenario containing EC/OC data (Fig. S1)). This is also supported by the results of the correlation analysis presented in Table 3, indicating that this factor has strong positive correlations with $\mathrm{PM}_{2.5}$, $\mathrm{NO}, \mathrm{NO}_{2}$, temperature, $\mathrm{RH}$, and SOC. The overall small contribution of this factor to the total number concentration was slightly higher in the cold phase than in the warm phase; this was the case both in terms of percent contribution $(2.5 \%$ in the cold phase vs. $1.5 \%$ in the warm phase) and number concentration $\left(111 \pm 11\right.$ particles $\mathrm{cm}^{-3}$ in the cold phase vs. $100 \pm 5$ particles $\mathrm{cm}^{-3}$ in the warm phase) (Figs. 5 and 6 and Table S1). The diurnal variation for this factor also reveals a significant increase during nighttime, especially dur- 
ing the cold phase (Fig. 7). However, the weekday/weekend analysis did not reveal any distinctive trend pertaining to the day of the week for this factor (Fig. 8). These pieces of evidence point to secondary aerosols as the most appropriate title for this factor, which is consistent with the results of previous PMF studies both on number size distributions and chemical speciation data (Beddows et al., 2015; Hasheminassab et al., 2014a). Table 3 indicates a much higher correlation of this factor with SOC than POC ( $R$ values of 0.5 and 0.2 , respectively). The association of this factor with $\mathrm{RH}$ and temperature, along with its higher contribution to particle number during the cold phase, particularly at night, supports the hypothesis that this factor likely represents the fraction of aerosols produced by secondary reactions on a regional scale, including ammonium nitrate (whose partitioning in the PM phase increases with decreasing temperature and increased $\mathrm{RH}$ ), but also secondary organic aerosols from nighttime and/or aqueous phase reactions, as indicated in earlier studies in this area (Hersey et al., 2011; Venkatachari et al., 2005). In a previous source apportionment study on $\mathrm{PM}_{2.5}$ chemical speciation data in downtown Los Angeles, we also found a similar factor profile, representing a mixture of secondary components (dominated by secondary nitrate and SOC) with a higher contribution during the cold season (Hasheminassab et al., 2014a). Moreover, previous studies have shown that secondary organic aerosol, formed at nighttime, together with ammonium nitrate are major contributors to the mass concentrations of $\mathrm{PM}_{2.5}$, which was also observed in the present work from the high loading of $\mathrm{PM}_{2.5}$ mass concentration in this profile (Fig. 3) (Hasheminassab et al., 2014a; Arhami et al., 2010; Saffari et al., 2016).

Factor 6: Factor 6 is dominated by particles at around $1 \mu \mathrm{m}$ and above (Fig. 3). This factor also had a volume mode at $>1 \mu \mathrm{m}$ (Fig. 4). Although this factor contributes only $1.1 \%$ $(0.2-6.3 \%)$ to the total number concentration (Fig. 5), it is associated with high loadings of coarse $\mathrm{PM}$ and $\mathrm{PM}_{2.5}$ (great contributor to mass) (Fig. 3). In addition, high loadings of temperature and wind speed were observed for this factor (Fig. 3). Table 3 also indicates strong correlation of this factor with coarse $\mathrm{PM}, \mathrm{PM}_{2.5}$, temperature, and wind speed. The contribution of this factor to the total number concentration was also higher in the warm phase than in the cold phase, both in terms of percent contribution $(0.2 \%$ in the cold phase vs. $6.3 \%$ in the warm phase) and number concentration ( $14 \pm 1$ particles $\mathrm{cm}^{-3}$ in the cold phase vs. $243 \pm 3$ particles $\mathrm{cm}^{-3}$ in the warm phase) (Figs. 5 and 6 and Table S1). The diurnal variations for this factor exhibited significantly higher contributions during daytime, especially in the warm phase (Fig. 7), when the atmosphere is unstable, wind speed is high, and the mixing height is at its maximum (Fig. 1). However, the weekday/weekend analysis did not reveal any distinctive trend pertaining to the day of the week for this factor (Fig. 8). Based on all of the above-mentioned characteristics, this factor was named soil/road dust (Gietl et al., 2010; Harrison et al., 2001, 2012). This is also quite con- sistent with the findings of the study of Hasheminassab et al. (2014a), in which the authors apportioned the sources of ambient fine particulate matter across the state of California. In that study, the authors observed a lower contribution of the soil factor to particle mass concentrations in the northern regions of the state of California, mainly because of higher RH and increased precipitation that inhibit the resuspension of soil due to strong winds (Harrison et al., 2001). In the present study, similarly, the contribution of this factor was higher in the warm phase, when higher temperatures and wind speeds facilitate the resuspension of soil and dust (Fig. 1).

\section{Summary and conclusions}

The present study was the first attempt to characterize major sources of PM number concentrations and to quantify their contributions using the PMF receptor model applied on $\mathrm{PM}$ number size distributions in the range of $13 \mathrm{~nm}$ to $10 \mu \mathrm{m}$ combined with several auxiliary variables, including BC, EC/OC, PM mass, gaseous pollutants, meteorological, and traffic flow data, in central Los Angeles. The six-factor solution was found to be the most physically applicable solution for the input data: nucleation, traffic 1 , traffic 2 , urban background aerosol, secondary aerosol, and soil. Traffic sources (1 and 2) were the major contributor to PM number concentrations, making up to above $60 \%$ of the total number concentrations combined, with larger contributions in the cold phase compared to the warm phase, when lower temperatures, wind speeds, and solar radiation lead to increased atmospheric stability and lower mixing height. The contribution of traffic factors was largest during morning and afternoon rush hours; it was also higher in the weekdays compared to the weekends, as expected. In agreement with the findings of previous studies in Los Angeles, nucleation was another major factor contributing to the total number concentrations $(17 \%)$, with a larger contribution in the warm phase than in the cold phase. The diurnal variations for this factor also revealed a sharp peak in the afternoon (14:00-18:00), which coincides with high temperatures, wind speeds, and solar radiation as well as with minimum RH, providing ideal conditions for the occurrence of photochemical nucleation processes, especially during warmer seasons. Urban background aerosol, secondary aerosol, and soil, with relative contributions of approximately $12,2.1$, and $1.1 \%$, respectively, overall accounted for approximately $15 \%$ of PM number concentrations. However, these factors dominated the PM volume and mass concentrations, due mainly to their larger mode diameters.

\section{The Supplement related to this article is available online at doi:10.5194/acp-16-4849-2016-supplement.}


Acknowledgements. The authors wish to acknowledge the support from the USC Viterbi School of Engineering's PhD fellowship award.

Edited by: X. Querol

\section{References}

Alleman, L. Y., Lamaison, L., Perdrix, E., Robache, A., and Galloo, J.-C.: PM $_{10}$ metal concentrations and source identification using positive matrix factorization and wind sectoring in a French industrial zone, Atmos. Res., 96, 612-625, 2010.

Arhami, M., Minguillón, M. C., Polidori, A., Schauer, J. J., Delfino, R. J., and Sioutas, C.: Organic compound characterization and source apportionment of indoor and outdoor quasi-ultrafine particulate matter in retirement homes of the Los Angeles Basin, Indoor Air, 20, 17-30, 2010.

Beddows, D. C. S., Harrison, R. M., Green, D. C., and Fuller, G. W.: Receptor modelling of both particle composition and size distribution from a background site in London, UK, Atmos. Chem. Phys., 15, 10107-10125, doi:10.5194/acp-15-10107-2015, 2015.

Brines, M., Dall'Osto, M., Beddows, D. C. S., Harrison, R. M., Gómez-Moreno, F., Núñez, L., Artíñano, B., Costabile, F., Gobbi, G. P., Salimi, F., Morawska, L., Sioutas, C., and Querol, $\mathrm{X}$.: Traffic and nucleation events as main sources of ultrafine particles in high-insolation developed world cities, Atmos. Chem. Phys., 15, 5929-5945, doi:10.5194/acp-15-5929-2015, 2015.

Brook, R. D., Rajagopalan, S., Pope, C. A., Brook, J. R., Bhatnagar, A., Diez-Roux, A. V., Holguin, F., Hong, Y., Luepker, R. V., and Mittleman, M. A.: Particulate matter air pollution and cardiovascular disease an update to the scientific statement from the American Heart Association, Circulation, 121, 2331-2378, 2010.

Brown, S. G., Eberly, S., Paatero, P., and Norris, G. A.: Methods for estimating uncertainty in PMF solutions: Examples with ambient air and water quality data and guidance on reporting PMF results, Sci. Total Environ., 518, 626-635, 2015.

Brunekreef, B. and Forsberg, B.: Epidemiological evidence of effects of coarse airborne particles on health, Eur. Respir. J., 26, 309-318, 2005.

Burtscher, H.: Physical characterization of particulate emissions from diesel engines: a review, J. Aerosol Sci., 36, 896-932, 2005.

Charron, A. and Harrison, R. M.: Primary particle formation from vehicle emissions during exhaust dilution in the roadside atmosphere, Atmos. Environ., 37, 4109-4119, 2003.

Chen, G., Ziemba, L. D., Chu, D. A., Thornhill, K. L., Schuster, G. L., Winstead, E. L., Diskin, G. S., Ferrare, R. A., Burton, S. P., Ismail, S., Kooi, S. A., Omar, A. H., Slusher, D. L., Kleb, M. M., Reid, J. S., Twohy, C. H., Zhang, H., and Anderson, B. E.: Observations of Saharan dust microphysical and optical properties from the Eastern Atlantic during NAMMA airborne field campaign, Atmos. Chem. Phys., 11, 723-740, doi:10.5194/acp11-723-2011, 2011.

Chen, L. C., Peoples, S. M., and Amdur, M. O.: Pulmonary effects of sulfur oxides on the surface of copper oxide aerosol, Am. Ind. Hyg. Assoc. J., 52, 187-191, 1991.
Covert, D. S., Heintzenberg, J., and Hansson, H.-C.: Electro-optical detection of external mixtures in aerosols, Aerosol Sci. Tech., 12, 446-456, 1990.

Dall'Osto, M., Beddows, D. C. S., Pey, J., Rodriguez, S., Alastuey, A., Harrison, R. M., and Querol, X.: Urban aerosol size distributions over the Mediterranean city of Barcelona, NE Spain, Atmos. Chem. Phys., 12, 10693-10707, doi:10.5194/acp-1210693-2012, 2012.

Davis, D. A., Bortolato, M., Godar, S. C., Sander, T. K., Iwata, N., Pakbin, P., Shih, J. C., Berhane, K., McConnell, R., and Sioutas, C.: Prenatal exposure to urban air nanoparticles in mice causes altered neuronal differentiation and depression-like responses, PLoS One, 8, e64128, doi:10.1371/journal.pone.0064128, 2013.

Day, M. C., Zhang, M., and Pandis, S. N.: Evaluation of the ability of the EC tracer method to estimate secondary organic carbon, Atmos. Environ., 112, 317-325, 2015.

Delfino, R. J., Sioutas, C., and Malik, S.: Potential role of ultrafine particles in associations between airborne particle mass and cardiovascular health, Environ. Health Persp., 113, 934-946, 2005.

Delfino, R. J., Tjoa, T., Gillen, D. L., Staimer, N., Polidori, A., Arhami, M., Jamner, L., Sioutas, C., and Longhurst, J.: Traffic-related Air Pollution and Blood Pressure in Elderly Subjects With Coronary Artery Disease, Epidemiology (Cambridge, Mass.), Vol. 21, doi:10.1097/EDE.0b013e3181d5e19b, 2010.

Dockery, D. W. and Stone, P. H.: Cardiovascular risks from fine particulate air pollution, N. Engl. J. Med., 356, 511-513, 2007.

Donaldson, K., Li, X. Y., and MacNee, W.: Ultrafine (nanometre) particle mediated lung injury, J. Aerosol Sci., 29, 553-560, 1998.

Dreher, K. L., Jaskot, R. H., Lehmann, J. R., Richards, J. H., Ghio, J. K. M. A. J., and Costa, D. L.: Soluble transition metals mediate residual oil fly ash induced acute lung injury, J. Toxicol. Env. Heal. A, 50, 285-305, 1997.

Dutton, S. J., Vedal, S., Piedrahita, R., Milford, J. B., Miller, S. L., and Hannigan, M. P.: Source apportionment using positive matrix factorization on daily measurements of inorganic and organic speciated $\mathrm{PM}_{2.5}$, Atmos. Environ., 44, 2731-2741, 2010.

Ebert, M., Weinbruch, S., Hoffmann, P., and Ortner, H. M.: The chemical composition and complex refractive index of rural and urban influenced aerosols determined by individual particle analysis, Atmos. Environ., 38, 6531-6545, 2004.

Friend, A. J., Ayoko, G. A., Jayaratne, E. R., Jamriska, M., Hopke, P. K., and Morawska, L.: Source apportionment of ultrafine and fine particle concentrations in Brisbane, Australia, Environ. Sci. Pollut. R., 19, 2942-2950, 2012.

Friend, A. J., Ayoko, G. A., Jager, D., Wust, M., Jayaratne, E. R., Jamriska, M., and Morawska, L.: Sources of ultrafine particles and chemical species along a traffic corridor: comparison of the results from two receptor models, Environ. Chem., 10, 54-63, 2013.

Gauderman, W. J., Urman, R., Avol, E., Berhane, K., McConnell, R., Rappaport, E., Chang, R., Lurmann, F., and Gilliland, F.: Association of improved air quality with lung development in children, N. Engl. J. Med., 372, 905-913, 2015.

Geller, M. D., Fine, P. M., and Sioutas, C.: The relationship between real-time and time-integrated coarse $(2.5-10 \mu \mathrm{m})$, intermodal (1$2.5 \mu \mathrm{m})$, and fine $(<2.5 \mu \mathrm{m})$ particulate matter in the Los Angeles Basin, J. Air Waste Manage., 54, 1029-1039, 2004.

Gietl, J. K., Lawrence, R., Thorpe, A. J., and Harrison, R. M.: Identification of brake wear particles and derivation of a quantitative 
tracer for brake dust at a major road, Atmos. Environ., 44, 141146, 2010.

Gu, J., Pitz, M., Schnelle-Kreis, J., Diemer, J., Reller, A., Zimmermann, R., Soentgen, J., Stoelzel, M., Wichmann, H. E., and Peters, A.: Source apportionment of ambient particles: comparison of positive matrix factorization analysis applied to particle size distribution and chemical composition data, Atmos. Environ., 45, 1849-1857, 2011.

Ham, W. A. and Kleeman, M. J.: Size-resolved source apportionment of carbonaceous particulate matter in urban and rural sites in central California, Atmos. Environ., 45, 3988-3995, 2011.

Hänel, G.: The real part of the mean complex refractive index and the mean density of samples of atmospheric aerosol particles, Tellus, 20, 371-379, 1968.

Harrison, R. M. and Yin, J.: Sources and processes affecting carbonaceous aerosol in central England, Atmos. Environ., 42, 1413-1423, 2008.

Harrison, R. M., Yin, J., Mark, D., Stedman, J., Appleby, R. S., Booker, J., and Moorcroft, S.: Studies of the coarse particle (2.5$10 \mu \mathrm{m})$ component in UK urban atmospheres, Atmos. Environ., 35, 3667-3679, 2001.

Harrison, R. M., Beddows, D. C. S., and Dall'Osto, M.: PMF analysis of wide-range particle size spectra collected on a major highway, Environ. Sci. Technol., 45, 5522-5528, 2011.

Harrison, R. M., Jones, A. M., Gietl, J., Yin, J., and Green, D. C.: Estimation of the contributions of brake dust, tire wear, and resuspension to nonexhaust traffic particles derived from atmospheric measurements, Environ. Sci. Technol., 46, 6523-6529, 2012

Harrison, R. M., Jones, A. M., Beddows, D. C. S., Dall'Osto, M., and Nikolova, I.: Evaporation of traffic-generated nanoparticles during advection from source, Atmos. Environ., 125, 1-7, 2016.

Hasheminassab, S., Daher, N., Schauer, J. J., and Sioutas, C.: Source apportionment and organic compound characterization of ambient ultrafine particulate matter (PM) in the Los Angeles Basin, Atmos. Environ., 79, 529-539, 2013.

Hasheminassab, S., Daher, N., Saffari, A., Wang, D., Ostro, B. D., and Sioutas, C.: Spatial and temporal variability of sources of ambient fine particulate matter $\left(\mathrm{PM}_{2.5}\right)$ in California, Atmos. Chem. Phys., 14, 12085-12097, doi:10.5194/acp-1412085-2014, 2014a.

Hasheminassab, S., Pakbin, P., Delfino, R. J., Schauer, J. J., and Sioutas, C.: Diurnal and seasonal trends in the apparent density of ambient fine and coarse particles in Los Angeles, Environ. Pollut., 187, 1-9, 2014b.

Hering, S. V. and McMurry, P. H.: Optical counter response to monodisperse atmospheric aerosols, Atmos. Environ., 25, 463468, 1991.

Hersey, S. P., Craven, J. S., Schilling, K. A., Metcalf, A. R., Sorooshian, A., Chan, M. N., Flagan, R. C., and Seinfeld, J. H.: The Pasadena Aerosol Characterization Observatory (PACO): chemical and physical analysis of the Western Los Angeles basin aerosol, Atmos. Chem. Phys., 11, 7417-7443, doi:10.5194/acp11-7417-2011, 2011.

Hudda, N., Cheung, K., Moore, K. F., and Sioutas, C.: Intercommunity variability in total particle number concentrations in the eastern Los Angeles air basin, Atmos. Chem. Phys., 10, 11385-11399, doi:10.5194/acp-10-11385-2010, 2010.
Hwang, I. and Hopke, P. K.: Comparison of source apportionments of fine particulate matter at two San Jose Speciation Trends Network sites, J. Air Waste Manage., 56, 1287-1300, 2006.

Janhäll, S., Jonsson, Å. M., Molnár, P., Svensson, E. A., and Hallquist, M.: Size resolved traffic emission factors of submicrometer particles, Atmos. Environ., 38, 4331-4340, 2004.

Kasumba, J., Hopke, P. K., Chalupa, D. C., and Utell, M. J.: Comparison of sources of submicron particle number concentrations measured at two sites in Rochester, NY, Sci. Total Environ., 407, 5071-5084, 2009.

Kent, G. S., Yue, G. K., Farrukh, U. O., and Deepak, A.: Modeling atmospheric aerosol backscatter at $\mathrm{CO}_{2}$ laser wavelengths. 1: Aerosol properties, modeling techniques, and associated problems, Appl. Optics, 22, 1655-1665, 1983.

Kim, E. and Hopke, P. K.: Source characterization of ambient fine particles in the Los Angeles basin, J. Environ. Eng. Sci., 6, 343 353, 2007.

Kim, E., Hopke, P. K., Larson, T. V., and Covert, D. S.: Analysis of ambient particle size distributions using unmix and positive matrix factorization, Environ. Sci. Technol., 38, 202-209, 2004.

Kim, E., Turkiewicz, K., Zulawnick, S. A., and Magliano, K. L.: Sources of fine particles in the South Coast area, California, Atmos. Environ., 44, 3095-3100, 2010.

Krecl, P., Hedberg Larsson, E., Ström, J., and Johansson, C.: Contribution of residential wood combustion and other sources to hourly winter aerosol in Northern Sweden determined by positive matrix factorization, Atmos. Chem. Phys., 8, 3639-3653, doi:10.5194/acp-8-3639-2008, 2008.

Li, N., Sioutas, C., Cho, A., Schmitz, D., Misra, C., Sempf, J., Wang, M., Oberley, T., Froines, J., and Nel, A.: Ultrafine particulate pollutants induce oxidative stress and mitochondrial damage, Environ. Health Persp., 111, 455-460, 2003.

Lighty, J. S., Veranth, J. M., and Sarofim, A. F.: Combustion aerosols: factors governing their size and composition and implications to human health, J. Air Waste Manage., 50, 1565-1618, 2000.

Lim, H.-J. and Turpin, B. J.: Origins of primary and secondary organic aerosol in Atlanta: Results of time-resolved measurements during the Atlanta supersite experiment, Environ. Sci. Technol., 36, 4489-4496, 2002.

Lim, J.-M., Lee, J.-H., Moon, J.-H., Chung, Y.-S., and Kim, K.-H.: Source apportionment of $\mathrm{PM}_{10}$ at a small industrial area using Positive Matrix Factorization, Atmos. Res., 95, 88-100, 2010.

Lim, S. S., Vos, T., Flaxman, A. D., Danaei, G., Shibuya, K., AdairRohani, H., AlMazroa, M. A., Amann, M., Anderson, H. R., and Andrews, K. G.: A comparative risk assessment of burden of disease and injury attributable to 67 risk factors and risk factor clusters in 21 regions, 1990-2010: a systematic analysis for the Global Burden of Disease Study 2010, Lancet, 380, 2224-2260, 2013.

Liu, Z. R., Hu, B., Liu, Q., Sun, Y., and Wang, Y. S.: Source apportionment of urban fine particle number concentration during summertime in Beijing, Atmos. Environ., 96, 359-369, 2014.

Miller, K. A., Siscovick, D. S., Sheppard, L., Shepherd, K., Sullivan, J. H., Anderson, G. L., and Kaufman, J. D.: Long-term exposure to air pollution and incidence of cardiovascular events in women, N. Engl. J. Med., 356, 447-458, 2007.

Moore, K. F., Ning, Z., Ntziachristos, L., Schauer, J. J., and Sioutas, C.: Daily variation in the properties of urban ultrafine aerosol - 
Part I: Physical characterization and volatility, Atmos. Environ., 41, 8633-8646, 2007.

Na, K., Sawant, A. A., Song, C., and Cocker, D. R.: Primary and secondary carbonaceous species in the atmosphere of Western Riverside County, California, Atmos. Environ., 38, 1345-1355, 2004.

Nel, A., Xia, T., Mädler, L., and Li, N.: Toxic potential of materials at the nanolevel, Science, 311, 622-627, 2006.

Norris, G., Duvall, R., Brown, S., and Bai, S.: EPA Positive Matrix Factorization (PMF) 5.0 Fundamentals and User Guide, U.S. Environmental Protection Agency, Office of Research and Development, Washington, DC 20460, 2014.

Ntziachristos, L., Ning, Z., Geller, M. D., and Sioutas, C.: Particle concentration and characteristics near a major freeway with heavy-duty diesel traffic, Environ. Sci. Technol., 41, 2223-2230, 2007

Oberdörster, G., Ferin, J., and Lehnert, B. E.: Correlation between particle size, in vivo particle persistence, and lung injury, Environ. Health Persp., 102, 173-179, 1994.

Oberdörster, G., Sharp, Z., Atudorei, V., Elder, A., Gelein, R., Lunts, A., Kreyling, W., and Cox, C.: Extrapulmonary translocation of ultrafine carbon particles following whole-body inhalation exposure of rats, J. Toxicol. Env. Heal. A, 65, 1531-1543, 2002.

Ogulei, D., Hopke, P. K., and Wallace, L. A.: Analysis of indoor particle size distributions in an occupied townhouse using positive matrix factorization, Indoor Air, 16, 204-215, 2006a.

Ogulei, D., Hopke, P. K., Zhou, L., Pancras, J. P., Nair, N., and Ondov, J. M.: Source apportionment of Baltimore aerosol from combined size distribution and chemical composition data, Atmos. Environ., 40, 396-410, 2006b.

Ogulei, D., Hopke, P. K., Chalupa, D. C., and Utell, M. J.: Modeling source contributions to submicron particle number concentrations measured in Rochester, New York, Aerosol Sci. Tech., 41, 179-201, 2007.

Paatero, P.: Least squares formulation of robust non-negative factor analysis, Chemometr. Intell. Lab., 37, 23-35, 1997.

Paatero, P. and Tapper, U.: Analysis of different modes of factor analysis as least squares fit problems, Chemometr. Intell. Lab., 18, 183-194, 1993.

Paatero, P. and Tapper, U.: Positive matrix factorization: A nonnegative factor model with optimal utilization of error estimates of data values, Environmetrics, 5, 111-126, 1994.

Paatero, P., Eberly, S., Brown, S. G., and Norris, G. A.: Methods for estimating uncertainty in factor analytic solutions, Atmos. Meas. Tech., 7, 781-797, doi:10.5194/amt-7-781-2014, 2014.

Peters, A., Wichmann, H. E., Tuch, T., Heinrich, J., and Heyder, J.: Respiratory effects are associated with the number of ultrafine particles, Am. J. Resp. Crit. Care, 155, 1376-1383, 1997.

Polidori, A., Arhami, M., Sioutas, C., Delfino, R. J., and Allen, R.: Indoor/outdoor relationships, trends, and carbonaceous content of fine particulate matter in retirement homes of the Los Angeles basin, J. Air Waste Manage., 57, 366-379, 2007.

Pope, C. A., III, Burnett, R. T., Thun, M. J., Calle, E. E., Krewski, D., Ito, K., and Thurston, G. D.: Lung cancer, cardiopulmonary mortality, and long-term exposure to fine particulate air pollution, Jama, 287, 1132-1141, 2002.

Pope, C. A., Burnett, R. T., Thurston, G. D., Thun, M. J., Calle, E. E., Krewski, D., and Godleski, J. J.: Cardiovascular mortality and long-term exposure to particulate air pollution epidemiological evidence of general pathophysiological pathways of disease, Circulation, 109, 71-77, 2004.

Reff, A., Eberly, S. I., and Bhave, P. V.: Receptor modeling of ambient particulate matter data using positive matrix factorization: review of existing methods, J. Air Waste Manage., 57, 146-154, 2007.

Reid, J. S., Cahill, T. A., Wakabayashi, P. H., and Dunlap, M. R.: Geometric/aerodynamic equivalent diameter ratios of ash aggregate aerosols collected in burning Kuwaiti well fields, Atmos. Environ., 28, 2227-2234, 1994.

Saffari, A., Hasheminassab, S., Shafer, M. M., Schauer, J. J., Chatila, T. A., and Sioutas, C.: Nighttime aqueous-phase secondary organic aerosols in Los Angeles and its implication for fine particulate matter composition and oxidative potential, Atmos. Environ., 133, 112-122, 2016.

Schauer, J. J. and Cass, G. R.: Source apportionment of wintertime gas-phase and particle-phase air pollutants using organic compounds as tracers, Environ. Sci. Technol., 34, 1821-1832, 2000.

Singh, M., Phuleria, H. C., Bowers, K., and Sioutas, C.: Seasonal and spatial trends in particle number concentrations and size distributions at the children's health study sites in Southern California, J. Expo. Sci. Env. Epid., 16, 3-18, 2006.

Sioutas, C., Delfino, R. J., and Singh, M.: Exposure assessment for atmospheric ultrafine particles (UFPs) and implications in epidemiologic research, Environ. Health Persp., 113, 947-955, 2005.

Sofowote, U. M., Su, Y., Dabek-Zlotorzynska, E., Rastogi, A. K., Brook, J., and Hopke, P. K.: Sources and temporal variations of constrained PMF factors obtained from multiple-year receptor modeling of ambient $\mathrm{PM}_{2.5}$ data from five speciation sites in Ontario, Canada, Atmos. Environ., 108, 140-150, 2015.

Sowlat, M. H., Naddafi, K., Yunesian, M., Jackson, P. L., and Shahsavani, A.: Source apportionment of total suspended particulates in an arid area in southwestern Iran using positive matrix factorization, B. Environ. Contam. Tox., 88, 735-740, 2012.

Sowlat, M. H., Naddafi, K., Yunesian, M., Jackson, P. L., Lotfi, S. and Shahsavani, A.: $\mathrm{PM}_{10}$ source apportionment in Ahvaz, Iran, using positive matrix factorization, CLEAN Soil Air Water, 41, 1143-1151, 2013.

Stolzenburg, M., Kreisberg, N., and Hering, S.: Atmospheric size distributions measured by differential mobility optical particle size spectrometry, Aerosol Sci. Tech., 29, 402-418, 1998.

Strader, R., Lurmann, F., and Pandis, S. N.: Evaluation of secondary organic aerosol formation in winter, Atmos. Environ., 33, 48494863, 1999.

Strawa, A. W., Elleman, R., Hallar, A. G., Covert, D., Ricci, K., Provencal, R., Owano, T. W., Jonsson, H. H., Schmid, B., and Luu, A. P.: Comparison of in situ aerosol extinction and scattering coefficient measurements made during the Aerosol Intensive Operating Period, J. Geophys. Res.-Atmos., 111, D05S03, doi:10.1029/2005JD006056, 2006.

Thimmaiah, D., Hovorka, J., and Hopke, P. K.: Source apportionment of winter submicron Prague aerosols from combined particle number size distribution and gaseous composition data, Aerosol Air Qual. Res., 9, 209-236, 2009.

Venkatachari, P., Hopke, P. K., Grover, B. D., and Eatough, D. J.: Measurement of particle-bound reactive oxygen species in $\mathrm{Ru}$ bidoux aerosols, J. Atmos. Chem., 50, 49-58, 2005. 
Venkataraman, C.: Comparison of particle lung doses from the fine and coarse fractions of urban PM-10 aerosols, Inhal. Toxicol., 11, 151-169, 1999.

Vu, T. V., Delgado-Saborit, J. M., and Harrison, R. M.: Review: Particle number size distributions from seven major sources and implications for source apportionment studies, Atmos. Environ., 122, 114-132, 2015.

Watson, J. G., Chow, J. C., Lowenthal, D. H., Stolzenburg, M. R., Kreisberg, N. M., and Hering, S. V.: Particle size relationships at the Fresno supersite, J. Air Waste Manage., 52, 822-827, 2002.

Wichmann, H.-E., Spix, C., Tuch, T., Wölke, G., Peters, A., Heinrich, J., Kreyling, W. G., and Heyder, J.: Daily mortality and fine and ultrafine particles in Erfurt, Germany part I: role of particle number and particle mass, Research report (Health Effects Institute), 98, 5-86, 2000.

Yue, W., Stölzel, M., Cyrys, J., Pitz, M., Heinrich, J., Kreyling, W. G., Wichmann, H. E., Peters, A., Wang, S., and Hopke, P. K.: Source apportionment of ambient fine particle size distribution using positive matrix factorization in Erfurt, Germany, Sci. Total Environ., 398, 133-144, 2008.
Zhang, K. M., Wexler, A. S., Niemeier, D. A., Zhu, Y. F., Hinds, W. C., and Sioutas, C.: Evolution of particle number distribution near roadways. Part III: Traffic analysis and on-road size resolved particulate emission factors, Atmos. Environ., 39, 41554166, 2005.

Zhou, L., Kim, E., Hopke, P. K., Stanier, C. O., and Pandis, S.: Advanced factor analysis on Pittsburgh particle size-distribution data special issue of aerosol science and technology on findings from the Fine Particulate Matter Supersites Program, Aerosol Sci. Tech., 38, 118-132, 2004.

Zhou, L., Hopke, P. K., Stanier, C. O., Pandis, S. N., Ondov, J. M., and Pancras, J. P.: Investigation of the relationship between chemical composition and size distribution of airborne particles by partial least squares and positive matrix factorization, J. Geophys. Res.-Atmos., 110, D07S18, doi:10.1029/2004JD005050, 2005. 